\title{
Nexus Between Energy Policy and Environmental Performance in China: The Moderating Role of Renewable Energy Patents.
}

\section{Muhammad Ghazanfar Abbas}

Ocean University of China

\section{Wang Zhuquan}

Ocean University of China

\section{Shahid Bashir}

Namal Institute

Wasim Iqbal ( $\nabla$ wasimiqbal@szu.edu.cn )

Shenzhen University

\section{Hafeez Ullah}

Ocean University of China

\section{Research Article}

Keywords: energy policy, Environmental performance, Non-radial DEA

Posted Date: April 26th, 2021

DOI: https://doi.org/10.21203/rs.3.rs-360120/v1

License: (9) This work is licensed under a Creative Commons Attribution 4.0 International License. Read Full License

Version of Record: A version of this preprint was published at Environmental Science and Pollution Research on July 5th, 2021. See the published version at https://doi.org/10.1007/s11356-021-15195-5. 
1 Nexus Between Energy Policy and Environmental Performance in China:

2 the Moderating Role of Renewable Energy Patents.

3 Muhammad Ghazanfar Abbas ${ }^{1}$, Wang Zhuquan ${ }^{1}$, Shahid Bashir ${ }^{2}$, Wasim Iqbal ${ }^{3}$, Hafeez 4 Ullah $^{1}$

\section{Abstract}

The socioeconomic and environmental considerations of energy production have become crucial due to the increasing complexity of the relationship between energy and the environment. In this context, this study aims to develop possible mechanisms for perspectives of energy policy on environmental by exploring the mediating role of renewable energy patents. The study used a non-radial data envelopment analysis (DEA) model and panel data model for 30 Chinese provinces by taking the panel data from 2010 to 2017. The results show that the overall environmental performance index (EPI) of Chinese areas is improved by $9.88 \%$ from 2010 to 2017. Further, The econometric model findings offer evidence that provincial renewable energy policies and emission reduction policies positively impact the enhancement of EPI. The results also show that the P values of the single-threshold model and the doublethreshold model both passed the $1 \%$ significance test, so it can be concluded that there is a double-threshold effect. Finally, the research findings posed several policy implications based on the research findings.

Keywords: energy policy; Environmental performance; Non-radial DEA

List of Abbreviations

\begin{tabular}{cl}
\hline Code & Variable Name \\
\hline EPI & Environmental performance index \\
EmRP & Emission reduction policies \\
RePO & Renewable energy policies \\
GDP & GDP of secondary industry \\
CEXP & Consumption expenditure \\
EDU & Educational level \\
RePat & Renewable energy patents \\
Pop & Total number of Population \\
InvP & Investment in anti-pollution projects \\
DEA & Data envelopment analysis \\
\hline
\end{tabular}


30 In the current ages, various researches are dedicated to measuring, investigating, and 31 enhancing energy efficiency. At that time, the environmental problem is a severe issue in the world. Mainly the question of the world's environmental problems due to the greenhouse emissions in which carbon-dioxide ( $\left.\mathrm{CO}_{2}\right)$, which generally connected to the blazing of fossil fuels. However, this process also becomes the source of wasteful usage of natural resources and significant environmental issues. Today the country that consumes considerable energy will also become the source of highly intense carbon dioxide (Ozturk and Acaravci, 2010), (Abbas et al., 2020) and (Anser et al., 2020). The government must shape a new planned objective that helps save natural resources, develop a healthy environment for enhancing energy efficiency and defending territory, and attain environmental development. Some countries are already declared that they reduce their co2 releases per unit of GDP by $40 \%$ to 45\% (Hou et al., 2019) and (Usman et al., 2021). At present, all nations are already facing enormous challenges of environmental issues. In this situation, these countries must enhance their energy efficiency and carefully think about environmental restrictions to lower their energy utilization and bring down environmental pollution (Iqbal et al., 2020), (Öztürk and Altınok, 2021). There are three types of index in which thermodynamic index, physical-based index, and currency-based indicators index. With index, we usually measure energy efficiency. The combined manufacturing procedure usually used energy such as natural gas, oil, and coal, etc. In this, labor and capital are also used to create unique productivity, e.g., GDP and unfortunate productivity, including emissions of pollutants $\left(\mathrm{CO}_{2}\right)$ and $\left(\mathrm{SO}_{2}\right)$ (Iqbal et al., 2019b). The environmental efficiency must not be unnoticed to deliver the more Similar type of Efficiency Mark.

Industries across the world consume more than one-third of the global energy. The proportion of $\mathrm{CO}_{2}$ emission is slightly higher in this regard. China's development model relies heavily on the industry, so local infrastructure development, manufacturing of export-oriented 
consumer products, and heavy industrial equipment are highly supported by energy-intensive production mechanisms. Therefore, the proportion of energy consumption concerning carbon emission is higher than the world average in China (Zhang et al., 2020)and (Iqbal et al., 2019a). The statistical report of 2010 from " the National Economic and Social Development states that processing the raw materials of petroleum and chemical products, melting and crashing of metal, non-metal and ferrous metal products, electricity generation and distribution are considered high energy-consuming activities. According to this report, all these sectors are segregated into sub-sector of Energy-intensive industries (Liu et al., 2019), (Iqbal et al., 2019c) and (Adedoyin et al., 2021). Due to the rise of energy intensity and subsequent carbon emission, China faced massive international criticism, and this led the government to initiate a low carbon emission policy in its $13^{\text {th }}$ five-year plan from 2016 to 2020 by setting a maximum carbon emission limit for all the energy-intensive companies of the country. It is determined in the program that the ferrous metal processing industry should decrease its energy use by a minimum of $10 \%$. In contrast, the petrochemical and nonferrous metal industries rate, in this regard, is $18 \%$ (Chen and Lin, 2020).

Since fossil energy is considered the main factor in global warming, emphasizing energyefficient production and distribution processes may be the key to solving this hazardous issue (Meng et al., 2020). Economic developments across the nation are correlated with energy intensity, carbon emission, and global warming issues. Therefore, businesses and governments should care about the human and wildlife, climate, and environmental aspects while setting up their respective growth strategies. In this connection, the green movement initiation by adopting green technology solutions for industrial production and distribution can be a useful undertaking. A robust energy and carbon management and control, if possible, with a strict regulatory framework and better energy policy can also improve the environmental quality to 
In the past two decades, China's economy has suffered several transformations and achieved significant economic structure progress. Though during this procedure, the environment of China has been seriously damaged. So, the combination of economic enhancement and environmental safety must be essential for China in the upcoming years. Decreasing the emission of pollutants, which creates terrible effects on public health and the environment, is one of China's primary goals. Environmental sustainability of the economy is generally measured with Environmental efficiency. Cities with environmentally efficient will also produce more economic output like revenues and less environmental output like greenhouse gasses. Using a more ecologically efficient decision-making unit will deliver us the most acceptable ecological and economic return for investment elements. Environmental resources will be used better with the help of an efficient decision-making unit.

This study aims to investigate the impact of energy policy on the environmental performance of China. This work contributes to the literature in the following three ways: First, the study used the non-radial DEA model to evaluate and compare China's EPIs at a provincial level (the non-radial DEA minimizes environmental pollution as it maximizes economic benefits). Second, the study used energy policy as a core variable and is further divided into emission reduction policies and renewable energy policies. Finally, with the help of the system GMM estimation method, the effectiveness of various environmental regulations is validated through our research; the nonlinear and heterogeneous effects of energy policy on provincial environmental performance are assessed.

100 The rest of the paper is structured as: section 2 review the relevant literature, section 3 101 explains the method and the indicators selected for the environmental performance index, $4^{\text {th }}$ section discusses the results, and finally, $5^{\text {th }}$ section presents the conclusion of the study and

103 further provides the policy implications for decision-makers

\section{Literature review}

In the manufacturing method, gases such as carbon dioxide and Sulfur dioxide are discharged in higher amounts using energy, and these gases will destroy the healthy 
107 environment. In real output productions, the point is used as the source of input, generally non-

108 renewable. Still, the labor and capital are renewable in the process of other non-energy

109 resources. To enhance energy efficiency and decrease pollutant releases, the non-renewable

110 energy inputs must be divide and protected as well as possible. We study some DEA-based

111 energy efficiency and environmental efficiency evaluation lessons in the later studies in which

112 the pollutant emissions are examined. Some DEA methods were used to evaluate the

113 environmental efficiency in 26 OECD countries from 1995-1997. In 2002 also assess the

114 efficiency with the help of this model in eight world counties. $\left(\mathrm{CO}_{2}\right)$, sulfur oxides $(\mathrm{SOx})$,

115 nitrogen oxides (NOx), and carbon monoxide (CO) as poor output, and a non-radial DEA

116 model are applied. Labor and main energy utilization as two inputs, and the one required result

117 is GDP. In the end, it is essential to select total energy consumption, GDP, and $\mathrm{CO}_{2}$ releases

118 that are taken in the form of only input, individual output, and low output. Various DEA-type

119 linear programming models used a dual output structure to calculate energy efficiency by using

120 energy and non-energy inputs over the economy and besides individual and poor output.

121 In recent times, different DEA models projected to measure the energy and resource

122 (energy) instantaneously. The hybrid power model tries to raise the individual output

123 consistently and decrease the low output to simultaneously estimate the total efficiency.

124 Therefore, the research is known as static analysis, so no alteration has been seen inefficiency

125 because they only measure one year's production. In various areas, they just estimated the

126 efficiency each year and easily measured production in different years where they overlooked

127 the technological progress, and efficiency is worse in multiple years. For every country, energy

128 plays a vital role in the rapid and complete development and the survival and development of

129 human civilization. The burning of coal creates $85 \%$ of $\mathrm{CO}_{2}$ emission, $73 \%$ of dust emission,

130 and $90 \%$ of $\mathrm{SO}_{2}$ emission. So, to handle energy consumption, climate change, maintain public

131 healthiness have real great importance. To build a pleasantly enhanced "Energy-Economy- 
132 Environment structure, we should reduce universal greenhouse gas emissions. In this way, a 133 prosperous society can be made in these countries.

134 In this fast-paced globalized world, energy is the core of strong economic growth, but this 135 energy is also the root cause of global climate change. In this case, decision-makers need to 136 formulate economic development strategies, taking into account environmental sustainability 137 issues. There is a mature argument that paying attention to energy-saving production 138 technology may be a significant measure to solve the current climate problem. Some studies 139 are supporting this claim. For example, Wang et al. (2017) studied the energy-saving potential 140 of 17 of the 17 Asia-Pacific Economic Cooperation (APEC) countries. Nassiri and Singh (2009)

141 evaluated the energy performance of 21 Organization for Economic Cooperation and 142 Development (OECD) countries by adopting both parametric and non-parametric approaches. 143 Khoshnevisan et al. (2013) also studied the energy efficiency of 23 developing economies and 144 concluded that the role of a strict energy policy is the key to ensure energy-efficient production 145 and the environment. Moreover, Geng et al.'s (2019) study on 15 EU countries revealed that 146 creating alternative energy sources and popularizing their use among industries and households 147 can reduce pressure on fossil energy and improve productivity comparatively. Meanwhile, 148 (Song et al. (2013) and (Li and Lin, 2017) studied the provincial energy efficiency of China 149 and concluded that technological advancement in the industry sector could lead to attaining 150 energy-efficient economic growth.

151 Researchers have adopted various energy efficiency measures to study the energy and 152 environmental efficiency levels of many different countries and regions. Data Envelopment 153 Analysis (DEA) is one of the most popular and useful tools for measuring energy and 154 environmental performance. Despite having some limitations, the DEA application has some 155 advantages in evaluating energy efficiency. This study reviews the DEA application used by 156 previous studies on energy and environmental efficiency and the decomposition of the 
157 Malmquist index. For example, ( Shao et al., 2014) and (Chen and Lin, 2020) applied DEA to 158 measure energy efficiency within the metal sector, and Ma et al. (2019) studied both energy 159 and pollution efficiency for the mining industry of China. Besides, Lin and Jia (2019) evaluated 160 the efficiency of environmental governance for China's energy industry.

161 Moreover, Yang et al. (2020) measured the energy efficiency of the manufacturing 162 industry by applying Malmquist index decomposition, Stochastic Frontier Method (SFA), and 163 meta frontier DEA method, and Lin and Chen (2019) measured the ecological efficiency of 164 the nonferrous metals industry of Chinese regions by applying non-radial DEA method. Du et 165 al. (2020) conducted another study to explore the green total factor production efficiency and 166 its determinants for the metal industry case in China with the application of sub-boundary and 167 global DEA approaches. Apart from these studies, several other studies were conducted on the energy and environmental coefficients for the steel, construction, and chemical industries of

169 Chinese provinces. It is observed that current literature is based mainly on environmental 170 performance. To the best of your knowledge, no prior studies objectively measured China's 171 ecological performance from the operational front. Also, it is observed that China is a vast 172 territory, and the different industrial sub-sectors that emerge along this territory affect the environmental performance (EP) of these regions. Therefore, by covering the heterogeneity of industries and areas, the total factor energy efficiency assessment of the six energy-intensive industries of Chinese provinces might help policymakers develop a sustainable strategy. It is

176 further observed that the non-radial DEA approach of efficiency measure is more flexible than

177 any other measurement technique as it can satisfy the requirements of maximized economic 178 growth and minimized pollution emissions. This study uses the non-radial DEA method for 179 the environmental performance index assessment of China at the provincial level. Due to the 180 extensive acceleration of ecological degradation, governments have undertaken many 181 corrective measures to tackle and promote sustainable development. It is currently unclear from 
the existing studies how different types of regional-level energy policies affect environmental performance. Therefore, investigating the effect of other regional level energy policies a timely attempt for ensuring an environmentally sustainable developed economy in China.

\section{3. Methodology}

\subsection{Model Construction}

187 Data envelopment analysis (DEA) is considered a more effective efficiency measurement tool than the conventional econometric approaches like regression or ratio analysis (Inman and Anderson et al., 2006)(Inman et al., 2006). Efficiency, in this case, has been defined by several

190 scholars. In this study, we consider Farrell's (1957)(Farrell, 1957) definition of efficiency, which was drawn from the study of (Koopmans 195) (Koopmann, 1951) to describe the measure of efficiency that constitutes multiple inputs. Farrell (1957)(Farrell, 1957) states that two components form an organization's efficiency: technical efficiency and allocative efficiency. In an input-oriented efficiency measurement, technical efficiency refers to the ratio of optimal input to the actual information. For an output-oriented efficiency measurement, it relates to the rate of real output to the optimal production.

On the other hand, allocative efficiency manifests an organization's ability to utilize its inputs optimally in respect to its prices and technology. Based on the objective of DecisionMaking Units (DMU), production frontier or cost frontier is used to determine the optimal input and optimal output. Two different methods are recommended in the literature in this regard: parametric and non-parametric approaches. A functional plan is assigned for the frontier in the parametric approach, but no preceding specification is applied for the nonparametric approach's border. (Charnes et al., 1978) followed the non-parametric process to develop the DEA model for measuring the single DMU's efficiency for the first time. They designed an input-oriented DEA model assuming a constant return to scale. However, the following studies of the DEA model considered different assumptions set. For example, 
207 (Banker, 1984) proposed variable returns to scale (VRS) and used mathematical programming 208 in their DEA model to generate a linear best practice frontier that relies on experimental input209 output data. This new DEA approach received wider acceptance for measuring the efficiency 210 of different DMUs across industries or countries.

211 Assume there are n DMUs and individually signifies an administration zone. Separately,

212 DMU's non-energy input and L energy input produce the predictable cost Output or low output 213 of K. DMUs helps make as much wanted production as possible and spent the resources in less 214 amount. Therefore, in the usual methods, the decreasing of pollutants is not allowable. This 215 trouble can be resolved using different methods like using the opposite of worse output, bad 216 behavior output as input, and statistically renovating the unwanted result into the desired 217 outcome. In the study of energy and environmental efficiency, low production is mostly produced by fossil fuels through manufacture, which must be minimized if we use energy in 219 less amount.

$$
\mathrm{EPI} 1=\min \theta
$$

$$
\begin{array}{ll}
\text { s.t. } \sum_{j=1}^{n} \lambda_{j} x_{i j}+s_{i}^{x-}=x_{i j 0}, i=1, \ldots, m, \sum_{j=1}^{n} \lambda_{j} e_{l j}+s_{l}^{e-}=\theta_{l}^{e} e_{l j 0}, \quad l= \\
1, \ldots L, \sum_{j=1}^{n} \lambda j y_{r j}-s_{r}^{y+}=y_{r j 0}, \quad r=1, \ldots s, \sum_{j=1}^{n} \lambda_{j} b_{k j}=\theta_{k}^{b} b_{k j}, \quad k=
\end{array}
$$
$1, \ldots, \mathrm{k}, \lambda_{\mathrm{j}}, \mathrm{S}_{\mathrm{i}}^{\mathrm{x}-}, \mathrm{S}_{\mathrm{l}}^{\mathrm{e}-}, \mathrm{S}_{\mathrm{r}}^{\mathrm{y}+} \geq 0$, for all $\mathrm{j}, \mathrm{i}, \mathrm{l}, \mathrm{r}$, ideal output and non-energy input. For sections between 0 and 1, the energy and environmental efficiency index is $\theta$, the superior the index, well the region's performance in terms of reducing pollutant discharges and energy saving. The corresponding part is measured to be energy and environmentally efficient. It cannot decrease its pollutant releases and energy consumption If EPI1 $=1(\theta=1)$ is zero, but if the EPI $<1(\theta<1)$ are not zero, then the corresponding region is environmentally inefficient, and can decrease energy utilization and pollutant discharges.

231 This type of model is the radial efficiency model. They may not have strong perceptions in energy efficiency assessments. 


$$
\mathrm{EPI}_{2}=\min \frac{1}{2}\left(\frac{1}{\mathrm{~L}} \sum_{\mathrm{l}=1}^{\mathrm{L}} \theta_{\mathrm{l}}^{\mathrm{e}}+\frac{1}{\mathrm{k}} \sum_{\mathrm{K}=1}^{\mathrm{k}} \theta_{\mathrm{k}}^{\mathrm{b}}\right)
$$

$$
\sum_{j=1}^{n} \lambda_{j} x_{i j}+s_{i}^{x-}=x_{i j 0,} i=1, \ldots, m, \sum_{j=1}^{n} \lambda_{j} e_{l j}+s_{l}^{e-}=\theta_{l}^{e} e_{l j 0}, \quad l=
$$

$$
1, \ldots L, \sum_{j=1}^{n} \lambda j y_{r j}-s_{r}^{y+}=y_{r j 0}, \quad r=1, \ldots s, \sum_{j=1}^{n} \lambda_{j} b_{k j}=\theta_{k}^{b} b_{k j}, \quad k=
$$

$$
1, \ldots, \mathrm{k}, \lambda_{\mathrm{j}}, \mathrm{S}_{\mathrm{i}}^{\mathrm{x}-}, \mathrm{S}_{\mathrm{l}}^{\mathrm{e}-}, \mathrm{S}_{\mathrm{r}}^{\mathrm{y}+} \geq 0, \text { for all } \mathrm{j}, \mathrm{i}, 1, \mathrm{r}
$$

This model decreases the energy utilization and pollutant discharges in various methods to attain top ideas with energy and environmental efficiency border. Energy efficiency and environmental efficiency consume altered non-proportional adjustments and investigate constant efficiency by elected choice creators. The environmental performance is unified in the efficiency equation and shows various partialities for an energy consumption presentation that decision-makers can give. We will use this method to estimate the total-factor energy and environmental efficiency of various areas because this model has a developed perceptive power than the 1 st model.

In this research, years between 2000 to 2008, we make a strategy to compute the energy and environmental efficiency in various areas. This forceful assessment can give us data about efficiency variations. However, It is more important and significant to discovering energy and the environment by putting on DEA window analysis to increase efficiency. The DEA window analysis method is used to develop time-varying data and cross-section data to compute dynamic properties. This method works by affecting medians and creates efficiency measures after this, treating every DMU as an individual unit at various times. Therefore, we find the environmental efficiency of various areas of different ages through overlapping windows using this technology.

During possible measurement of efficiency, it has been seen that the width of the window has tended to yield 3or 4 periods of time. This paper considers $(w=3)$ a window with three widths for attaining consistent environment and energy efficiency results. For such purpose, 257 the first three years, 2010 to 2012, have been utilized for the first window. After that, we will 
more for a further one-year window and release base year while adding the next one, and this

259 procedure will continue till the last window is installed. Thus, radial and non-radial

260 environmental energy efficiency (EPI1 \&EPI2) of each underlined province can be attained by

261 Appling DEA window analysis.

262 3.2 Data

263 In the above equation, we used three inputs labor, capital and energy use, one good output

264 provincial Gros regional product which used as proxy for GDP and one bad output $\mathrm{CO}_{2}$

265 emissions for environmental performance index over the period of 2010 to 2017. Table 1 shows

266 the descriptive statistics for the input and output variables of this study. The data for

267 input/output indicators is colleceted from National Bureaue of Statistics of China and China

268 database,(http://www.stats.gov.cn/english/Statisticaldata/AnnualData/)(https://www.dccchina

269 .org/services/china-data/).

270 Table 1. Descriptive statistics of input/output indicator for environmental performance index

\begin{tabular}{lllllll}
\hline & & $\begin{array}{l}\text { CO2 } \\
\text { emission }\end{array}$ & $\begin{array}{l}\text { Good } \\
\text { output }\end{array}$ & Input 1 & Input 2 & Input 3 \\
\hline 2010 & Max & 126.2 & 71.9 & 19.2 & 1435.1 & 24.4 \\
& Min & 3.7 & 1.6 & 1.3 & 0.7 & 0.3 \\
& Mean & 51.6 & 17.0 & 7.63 & 420.5 & 8.8 \\
& SD & 34.5 & 14.8 & 4.4 & 282.5 & 6.7 \\
2012 & Max & 267.8 & 243.9 & 20.5 & 2371.5 & 37.3 \\
& Min & 7.5 & 6.2 & 1.6 & 43.2 & 0.8 \\
& Mean & 90.7 & 53.6 & 8.4 & 825.0 & 14.3 \\
& SD & 66.8 & 51.5 & 4.9 & 537.5 & 10.5 \\
& Max & 373.9 & 436.4 & 22.0 & 5825.9 & 58.0 \\
& Min & 9.8 & 11.2 & 1.2 & 252.3 & 0.2 \\
& Mean & 131.2 & 107.0 & 9.2 & 2441.1 & 18.8 \\
& SD & 93.3 & 95.2 & 5.4 & 1325.0 & 13.5 \\
& Max & 453.9 & 761.2 & 20.4 & 12831.4 & 60.7 \\
& Min & 14.0 & 24.9 & 1.2 & 850.4 & 1.1 \\
& Mean & 148.2 & 182.8 & 9.4 & 5559.4 & 18.2 \\
& SD & 112.9 & 166.7 & 5.1 & 2911.8 & 14.1 \\
\hline
\end{tabular}

271 


\section{Empirical results and discussions}

\section{4.1 Environmental Performance}

274 Energy consumption in China increased from the 10-year average of $3.3 \%$ in 2017 and

$3.9 \%$ in 2018 to $4.3 \%$ in 2018 . China is still the world's largest energy consumer, accounting

276 for $24 \%$ of global energy consumption and 34\% of global energy demand growth in 2018.

277 Consuming fossil fuels was led by natural gas $(+18 \%)$ and oil $(+5.0 \%)$, while coal usage

278 increased for the second consecutive year. China's energy structure is continually evolving.

279 Although coal is still the primary fuel, its share of total energy consumption in $2018(58 \%)$ has

280 reached a historical low. China is the world's largest importer of oil and natural gas. The

281 dependence on oil imports rose to $72 \%$ in 2018 , the highest level in the past half-century. By

282 2018, the reliance on natural gas imports has increased to 43\%. Concerns about energy security

283 are growing. Among non-fossil fuels, solar energy consumption increased the fastest (51\%

284 increase), followed by wind energy ( $24 \%$ increase) and biomass and geothermal (14\%

285 increase). Hydropower increased by $3.2 \%$, almost a third of the 10-year average growth of 9.2

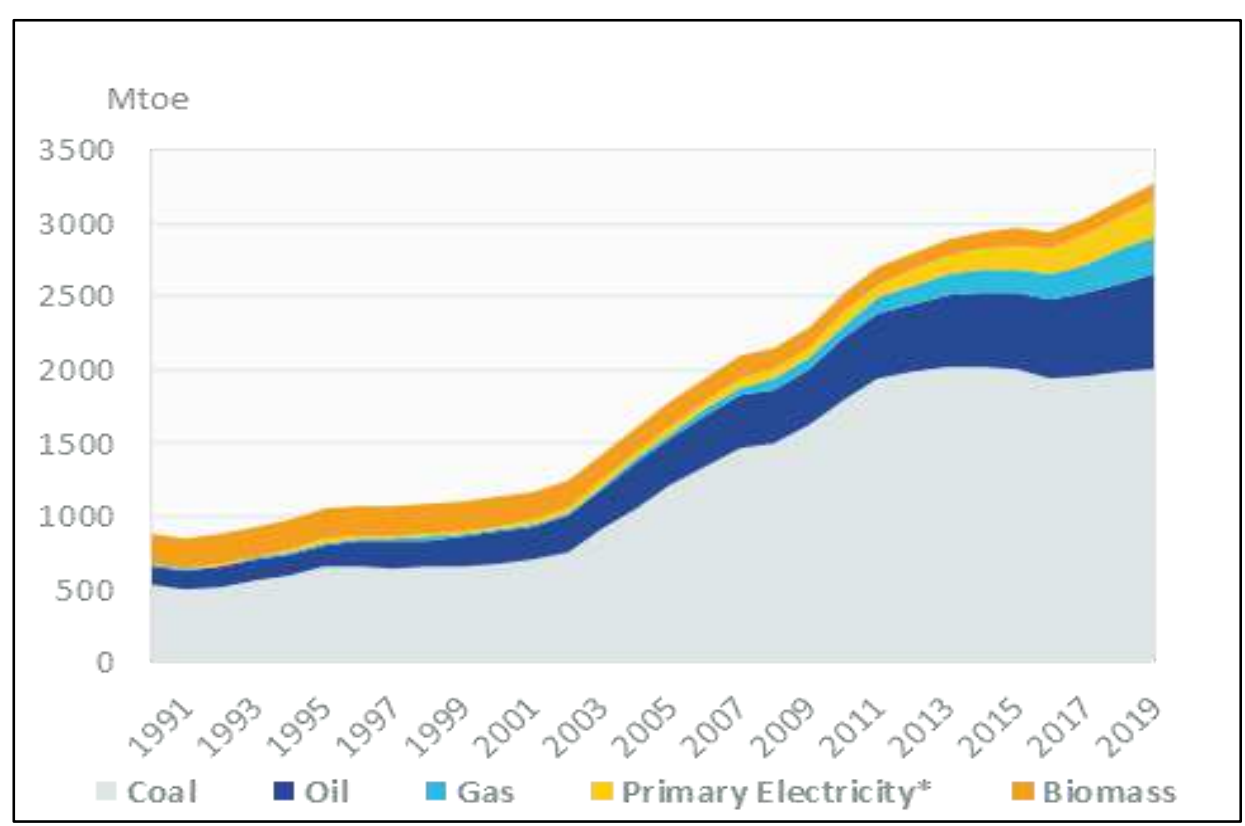

Fig. 1 Energy consumption by source 
291 Jiangsu, Zhejiang, Anhui, Jiangxi, Hubei, and Sichuan. The lowest EP is recorded in Shanxi,

292 Qinghai, Heilongjiang, Yunnan, Gansu, Xinjiang, and Ningxia. Provinces in central and 293 eastern regions have high EPI, and western and north-east areas have low EPI. Compared to 294 the east and central provinces, China's western provinces have a lower EPI due to a poor 295 economic foundation and backward technological level. The other reason behind low EPI is 296 due to high energy-intensive industries located in north-eastern China. The old industrial base 297 developed earlier with a soft EPI due to outdated equipment and severe environmental 298 pollution.

299 Table 2. The environmental performance index of China at the provincial level from 2010 to $300 \quad 2017$

\begin{tabular}{lrrrrrrrr}
\hline Province & 2010 & 2011 & 2012 & 2013 & 2014 & 2015 & 2016 & 2017 \\
\hline Guangdong & 0.9 & 0.891 & 0.9 & 0.9 & 0.882 & 0.9 & 0.855 & 0.882 \\
Hainan & 0.9 & 0.9 & 0.9 & 0.9 & 0.9 & 0.9 & 0.9 & 0.9 \\
Shanghai & 0.9 & 0.9 & 0.9 & 0.9 & 0.81 & 0.9 & 0.9 & 0.9 \\
Zhejiang & 0.9 & 0.9 & 0.891 & 0.9 & 0.855 & 0.846 & 0.873 & 0.828 \\
Jiangsu & 0.891 & 0.891 & 0.882 & 0.873 & 0.873 & 0.891 & 0.9 & 0.9 \\
Beijing & 0.846 & 0.792 & 0.873 & 0.837 & 0.792 & 0.9 & 0.9 & 0.9 \\
Fujian & 0.774 & 0.693 & 0.621 & 0.693 & 0.648 & 0.594 & 0.666 & 0.684 \\
Tianjin & 0.756 & 0.702 & 0.711 & 0.828 & 0.702 & 0.774 & 0.738 & 0.801 \\
Qinghai & 0.657 & 0.765 & 0.684 & 0.675 & 0.522 & 0.54 & 0.531 & 0.531 \\
Jiangxi & 0.558 & 0.468 & 0.441 & 0.468 & 0.513 & 0.432 & 0.414 & 0.459 \\
Gansu & 0.549 & 0.405 & 0.234 & 0.234 & 0.189 & 0.216 & 0.171 & 0.198 \\
Henan & 0.531 & 0.549 & 0.423 & 0.45 & 0.396 & 0.387 & 0.342 & 0.378 \\
Liaoning & 0.504 & 0.531 & 0.495 & 0.495 & 0.495 & 0.54 & 0.477 & 0.351 \\
Ningxia & 0.495 & 0.468 & 0.378 & 0.342 & 0.279 & 0.333 & 0.288 & 0.387 \\
Sichuan & 0.459 & 0.351 & 0.279 & 0.315 & 0.243 & 0.243 & 0.198 & 0.288 \\
Anhui & 0.441 & 0.369 & 0.495 & 0.531 & 0.495 & 0.612 & 0.441 & 0.567 \\
Hebei & 0.432 & 0.522 & 0.45 & 0.468 & 0.504 & 0.468 & 0.468 & 0.486 \\
Hubei & 0.387 & 0.36 & 0.342 & 0.396 & 0.351 & 0.459 & 0.423 & 0.513 \\
Chongqing & 0.369 & 0.459 & 0.333 & 0.396 & 0.234 & 0.306 & 0.297 & 0.342 \\
Guangxi & 0.369 & 0.414 & 0.306 & 0.315 & 0.333 & 0.351 & 0.333 & 0.351 \\
Jilin & 0.369 & 0.486 & 0.468 & 0.477 & 0.459 & 0.495 & 0.324 & 0.477 \\
Inner Mongolia & 0.315 & 0.378 & 0.342 & 0.351 & 0.351 & 0.468 & 0.396 & 0.324 \\
Hunan & 0.27 & 0.225 & 0.27 & 0.315 & 0.27 & 0.306 & 0.279 & 0.612 \\
Shaanxi & 0.261 & 0.243 & 0.189 & 0.675 & 0.18 & 0.243 & 0.252 & 0.324 \\
Guizhou & 0.225 & 0.27 & 0.153 & 0.18 & 0.135 & 0.288 & 0.243 & 0.333
\end{tabular}




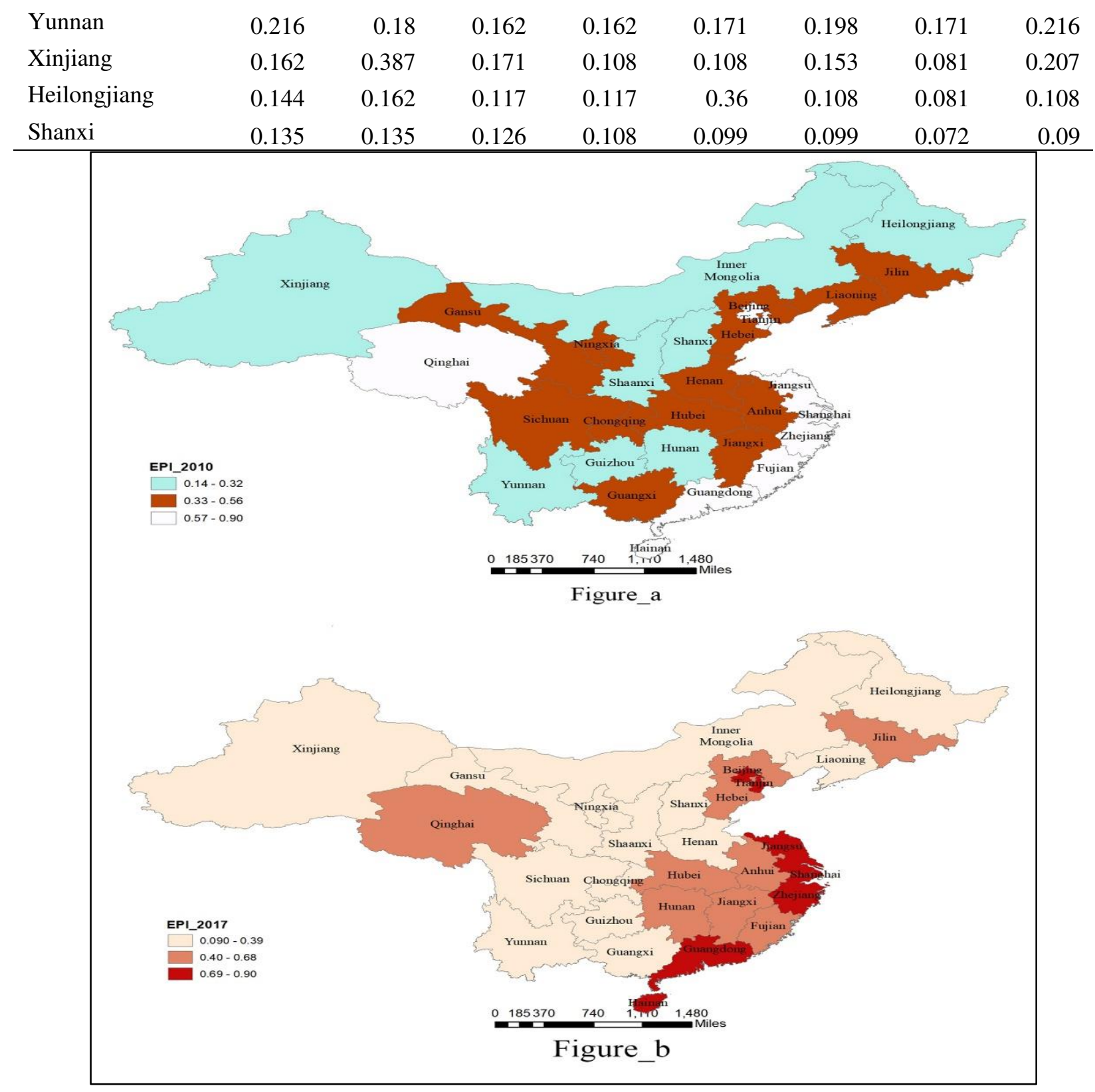

Figure 2 The spatial distribution of EPI in 2010 and 2017

304 Shandong, Zhejiang, Jiangsu, and Liaoning are recorded to have the highest EPI (0.82-1.00),

305 whereas Guizhou, Henan, Inner Mongolia, Heilongjiang, Yunnan, and Shanxi have the lowest

306 EP (0.07-0.20). According to Fig. 2b, an EPI score within the range of 0.74 to 1 is evident in

307 Jiangsu, Shandong, Guangdong, Hainan, Zhejiang, Shanghai, and Fujian. In contrast, with the score 0.07-0.26, Shanxi, Chongqing, Yunnan, Xinjiang, Heilongjiang, Sichuan, Hebei, Hubei,

309 Hunan, Guangxi, and Guizhou show lower values. Beijing, Shanghai, Jiangsu, Guangdong, 
310 and Hainan are considered the most environmentally efficient provinces. With a particular

311 focus on the western and north-eastern regions, China needs further improvement in

312 environmental performance at the provincial level. With better energy and pollution control

313 effect, Jiangxi and Sichuan show a relatively high EPI. EPI's worst value is recorded in the

314 central region of Shanxi, the western part of Xinjiang, Yunnan, and Gansu. A significantly

315 poor economic foundation, backward technological conditions, and low efficiency are evident

316 in the provinces mentioned above.

\section{4.2 Average Environmental Performance Index}

318 Figure 3 shows the average environmental performance index (EP) results from 2008 to

3192017 based on the non-radial DEA model. It can be seen that during the 2010 to 2017 study

320 period, the average EPI of China at the provincial level showed an upward trend. The average

321 EPI's overall story is still shallow, with an average value of 0.44 and 0.52 , far below the optimal

322 value of 1. China's industries consume large amounts of energy and emit large amounts of 323 carbon dioxide, resulting in low power and environmental performance. This shows that

324 China's industries are responsible for high levels of carbon dioxide emissions, which ultimately 325 makes china environmentally inefficient. However, China's government has emphasized 326 pollution control measures, and high emitting industries like petrochemical and metal will be 327 under severe environmental scrutiny. For this ecological regulatory initiative, EPI for high 328 carbon emission industries has dramatically increased. This finding also goes in line with (Wu et al., 2020), who investigated the efficiency of energy and Chinese provinces' environment. 


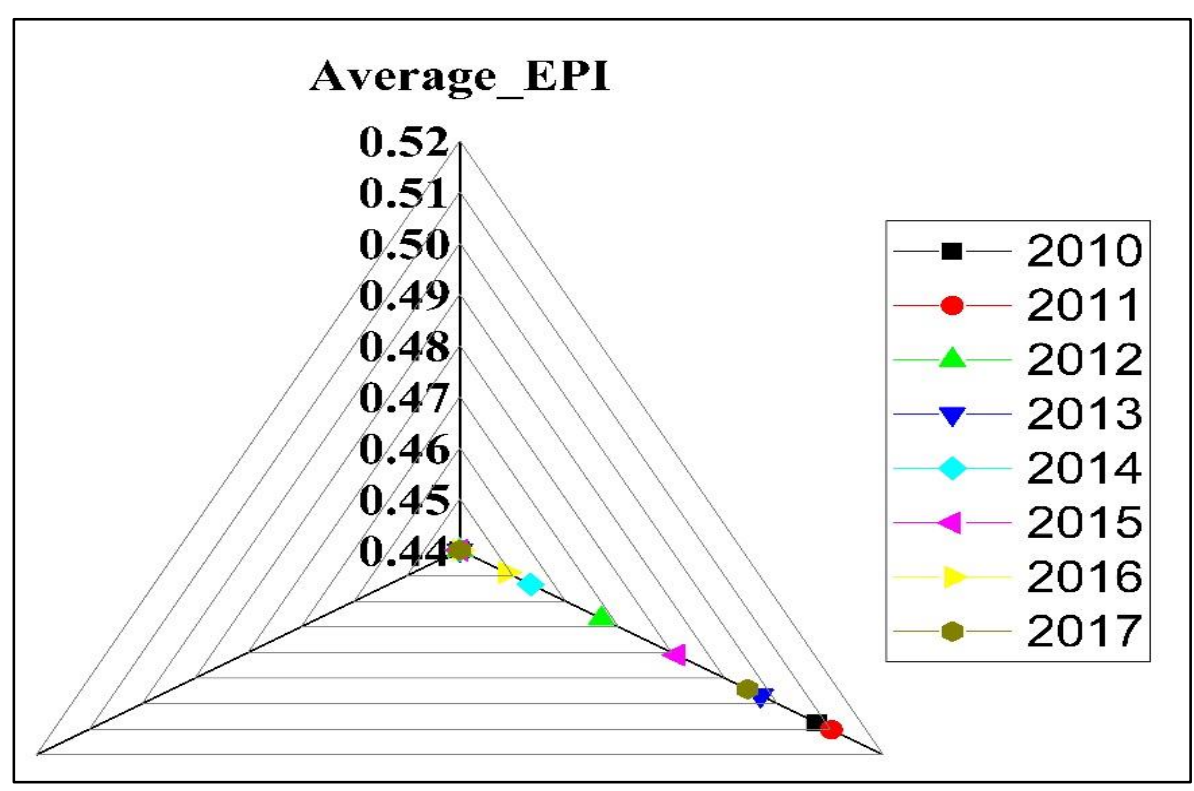

Figure 3. The average EPI of China's at the provincial level from 2010 to 2017

\subsection{Econometric modeling and variable selection}

\subsubsection{The Dynamic Panel Data Model Effect}

The following equation is constructed to find the relationship between environmental regulation and total factor energy efficiency:

$$
\mathrm{EPI}_{i t}=\alpha+\beta \mathrm{EPI}_{i, t-1}+\text { yenergy_policy }{ }_{i t}+\theta X_{i t}+u_{t}+v_{i}+\varepsilon_{i t}
$$

In this equation, $\alpha$ represents the intercept and $\beta, \gamma$ and $\theta$ are coefficients to be estimated. energy_policy $_{i t}$ is the independent variable, that is, the vector that represents the energy policy. $\mathrm{EPI}_{i, t-1}$ is the first lag term of $\mathrm{EPI}_{i t}$. This lagged dependent variable $\mathrm{EPI}_{i, t-1}$ is added as the independent variable in constructing the equation considering the impact of lagged environmental performance index on the current environmental performance index. $X_{i t}$ matrix indicates the control variables set. $u_{t}$ is fixed time effect, $v_{i}$ is a single fixed-effect, and $\varepsilon_{i t}$ is a random error term.

(a) Dependent variable: The dependent variable in this paper is environmental performance index.

(b) Independent variable: By providing economic incentives, services, new legislation or laws, and public education, current energy policies are expected to affect environmental 
348 performance. As mentioned earlier, the Chinese government's energy policy has been classified

349 as a reduction policy or a renewable energy policy. We use the current number of provincial

350 laws, regulations, and detailed plans as key independent policy variables. These steps are from

351 information collected on the Law Star website. To check and classify the provincial policies

352 belonging to each group, we used keywords such as "emission reduction" and "renewable

353 energy." In addition to energy policy variables in experience variables, socioeconomic and

354 environmental variables are also used as control variables to illustrate their environmental

355 performance impact. Social and economic variables include secondary industry GDP,

356 consumer spending, education level, and population density. Ecological variables include

357 emission levels of private cars, exhaust emissions, Investment in treatment of departmental

358 pollution sources, and Investment in anti-pollution programs. Investment in industrial waste

359 source treatment and pollution prevention programs is necessary financial support for

360 environmental pollution management. They are used as proxy variables to reflect the ecological

361 governance of government work. The data for the above variables comes from the "China

362 Environmental Statistical Yearbook" and "China Statistical Yearbook". All variables in the

363 table are expressed in their natural logarithm form. For each variable, there are 240

364 observations. Table 3 provides descriptive statistics for all variables.

365 Table 3. Descriptive statistics and data sources.

\begin{tabular}{ccccc}
\hline Variable & Mean & SD & Min & Max \\
\hline EPI & 4.579 & 0.338 & 2.708 & 5.72 \\
EeRp & 2.056 & 1.517 & 0 & 4.89 \\
RePo & 0.938 & 1.014 & 0 & 3.584 \\
GDP & 3.822 & 0.212 & 2.955 & 4.119 \\
CEXP & 9.382 & 0.459 & 8.5 & 10.59 \\
EDU & 8.026 & 0.257 & 7.021 & 8.503 \\
RePat & 4.714 & 1.263 & 2 & 7 \\
PopD & 3.88 & 0.295 & 3.037 & 4.495
\end{tabular}


InvP

4.322

1.673

$-2.303$

7.256

366

367

4.3.2 The Empirical Results of Panel data Model

368

The panel data model approach is applied to fix the issues relevant to dynamic panel

estimation stated in equation 3. System GMM takes into consideration that there is no auto-

370

correlation within the disturbance terms. This approach also solves the endogeneity issue by

371

taking lag variables. The result of the GMM test is presented in table 4. Apart from performing

372

the GMM, the study also conducted Arellano-bond (AR) test, Sargan-Hansen, and Wald chi-

373 square tests to attain a more robust estimation result. The Arellano-Bond (AR) test comprises both first and second-order auto-correlation of residuals tests which are known as AR (1) and AR (2), respectively. The equation's residuals are regarded as not autocorrelated if AR (2) is accepted and AR (1) is rejected. Meanwhile, to check the homogeneity among the variables, the Sargan-Hansen test is applied. Moreover, the Wald test is performed to check the level of significance of each regression.

379 Table 4. The result of the Panel Data regression

\begin{tabular}{|c|c|c|c|c|}
\hline \multirow[b]{2}{*}{ Constant } & \multicolumn{2}{|c|}{ Emission reduction policy } & \multicolumn{2}{|c|}{ Renewable energy policy } \\
\hline & $1.0384(0.117)$ & $1.0586 * * *(0.1225)$ & $1.1112 * * *(0.0519)$ & $1.1477 * * *(0.0701)$ \\
\hline EMRP & $0.0286 * * *(0.1551)$ & & & \\
\hline EMRP_lag & & $0.0342 * * *(0.1137)$ & & \\
\hline REPO & & & $0.0304 * * *(0.0052)$ & \\
\hline REPO_lag1 & & & & $0.0605 * * *(0.0761)$ \\
\hline GDP & $-0.0342 * * *(0.0011)$ & $-0.0350 * * *(0.0012)$ & $-0.0294 * * *(0.0203)$ & $-0.0301 * * *(0.0214)$ \\
\hline CEXP & $0.0151(0.0014)$ & $0.0160 *(0.0017)$ & $0.0209(0.0159)$ & $0.0241 *(0.0022)$ \\
\hline EDU & $0.03251 * * *(0.0445)$ & $0.03607 * * *(0.045)$ & $0.04251 * * *(0.0624)$ & $0.04399 * * *(0.0661)$ \\
\hline RePat & $0.0009 * *(0.0006)$ & $0.0011 * * *(0.0008)$ & $0.0010 * * *(0.0009)$ & $0.0012 * * *(0.001)$ \\
\hline Pop & $-0.0120 * * *(0.0038)$ & $-0.0135 * * *(0.004)$ & $-0.0201 * * *(0.0114)$ & $-0.0263 * * *(0.0118)$ \\
\hline InvP & $0.0293 * * *(0.0046)$ & $0.0311 * * *(0.0053)$ & $0.0413 * * *(0.0058)$ & $0.0438 * * *(0.0059)$ \\
\hline AR (1) test & -2.0632 & -2.0841 & -2.4149 & -2.5243 \\
\hline
\end{tabular}




\begin{tabular}{lcccc}
\hline & {$[0.023]$} & {$[0.023]$} & {$[0.019]$} & {$[0.013]$} \\
AR (2) test & -1.1591 & -1.2374 & -1.2580 & -1.3001 \\
& {$[0.171]$} & {$[0.138]$} & {$[0.166]$} & {$[0.154]$} \\
Sargan test & 21.3797 & 19.9903 & 23.5612 & 18.5531 \\
& {$[0.068]$} & {$[0.069]$} & {$[0.11]$} & {$[0.139]$} \\
Wald test & 176396 & 280449 & 192133 & 305156 \\
& {$[0]$} & {$[0]$} & {$[0]$} & {$[0]$} \\
$\mathbf{N}$ & 240 & 240 & 240 & 240 \\
\hline
\end{tabular}

Note: Standard errors are in parentheses (). ${ }^{* * *}=1 \%$ significant level; $* *=5 \%$ significant

381 level and $*=10 \%$ significant level

382 Table 4 shows the result of the panel data analysis for the variables under study with four

383 different models. It is observed that lagged EPI coefficients are positive and statistically

384 significant at a $1 \%$ significance level, showing that the present EPI performance is affected by

385 the previous period's EPI's performance. It is further observed that the coefficient of both

386 emission reduction (EmRP) and renewable energy policy (ReEP) is 0.0286 and 0.0304

387 respectively, the findings indicate that both EmPR and ReEP are statistically significant at $1 \%$

388 level. The results first confirmed that provincial renewable energy policies and emission

389 reduction had different effects on improving environmental performance. Our results are in

390 line with (Cariola et al., 2020), they reveals that energy policy positively influences the

391 improvement of environmental performance. This goes in line with the Porter effect for the

392 case of China. Our findings are also in line with majority of the existing literatures, for example,

393 (Hodson et al., 2018),(Galeotti et al., 2020), (Wang et al., 2020), (Yu and Wang, 2021).

394 Moreover, the results are in line with the conventional view that more investment in renewable

395 energy and pollution reduction leads to more renewable energy consumption and hence

396 contribute to environmental degradation.

397 Meanwhile, the control variables (see table 4) regression estimation shows that both GDP

398 and Population negatively affect the EPI at 1\% significant level in all cases. It means a $1 \%$

399 increase in GDP and Population reduces the environmental performance by $3.42 \%$ and $1.2 \%$, 
400 respectively. Our results in line with, (Yu and Wang, 2021), their findings indicate that a $1 \%$

401 increase in GDP and Population contributes to decrease environmental performance by $0.71 \%$ -

$4020.59 \%$. On the other hand, Investment in education and Investment in anti-pollution projects have

403 a significant positive effect at $1 \%$ significant level. It indicates that a $1 \%$ increase in education

404 investment and Investment in anti-pollution projects improves environmental performance by $3.25 \%$

405 and $2.93 \%$, respectively. This affirms that spending more on education and air pollution control

406 might help to improve environmental performance. On the other hand, renewable energy

407 patents have a positive effect on environmental performance. Besides, it is observed that

408 consumption expenditure has no significant influence on EPI improvement. These findings are

409 also in line with (Alam et al., 2019) who found a $1 \%$ increase in education help decrease in

410 firm environmental performance by $2.89 \%$.

411 Considering the probable lag effect of energy policy, the estimation of emission reduction

412 policy and renewable energy policy is performed taking the lagged value of EmRP and RePo.

413 The results show the same scenario as the baseline regression as it is seen that there is the

414 existence of statistically significant EmRP over EPI, and the control variables also consistent

415 with the estimated coefficients. However, for the case of RePo, the coefficients (0.0605) of

416 lagged variables are found to be positive and statistically significant at $1 \%$ level, proving that

417 environmental performance is affected by the lag terms (table 4). It refers to the fact that in

418 the case of a rigorous CCER practice, the influence of "innovation offset" is more powerful

419 than the result of the "compliance cost" effect in the long run. This proposition matches with

420 the findings of Guo and Yuan (2020). They argue that taking the lagged variables instead of

421 current variables might increase to chances to generate a positive and significant effect on

422 energy efficiency. 


\subsubsection{The Moderating Effect of Renewable Energy Patents}

Table 5 presents results of the moderating effect of renewable energy patents on the environmental performance of China. The moderating impact's findings indicate that all the moderating coefficients are positive and statistically significant with a $1 \%$ level. This proposes that the moderating effect of renewable energy patents (RePat) existent for energy policy. The result of the regression estimation shows that a greater number of RePat can boost EPI. Porter argues that, by making a well-structured energy policy based on the renewable energy patents effect, a positive effect can be established on renewable energy patents and technology empowerment. Therefore, the moderation effect of renewable energy patents and energy policy on EPI needs to be studied further to enhance EPI to the highest level possible. The moderating

433 factors of renewable energy patents and energy policy are included in this study's dynamic 434 panel modeling. The results are in line with (Böhringer et al., 2017; Li and Lin, 2016; Miyamoto and Takeuchi, 2019), their findings conclude that renewable energy have significant negative impact on environmental pollution. The results of the study are also in line with the study of (Alam et al., 2019), they check heterogeneous impacts of environmental and renewable energy patents on $\mathrm{CO}_{2}$ emission. They find environmental and renewable energy

439 patents have negative impact on carbon emission which is ultimately environmental 440 performance.

441 Table 5. Regression results of renewable energy patents effect on EPI.

\begin{tabular}{lllll}
\hline & EmRP & RePO & EmRP & RePO \\
\hline EPI_lag1 & $0.3711 * * *((0.0026)$ & $0.3996 * *(0.0011)$ & $0.4028 * * *((0.0031)$ & $0.4154 * * *(0.0013)$ \\
Constant & $1.1383 * * *(0.0390)$ & $1.1099 * * *(0.0590)$ & $1.2353 * * *(0.0490)$ & $1.0723 * * *(0.0590)$ \\
EmRP & $0.0293 * * *(0.0556)$ & & & \\
EmRP_lag1 & $0.0415 * * *(0.0603)$ & & & \\
RePO & & $0.0322 * *(0.0046)$ & \\
RePO_lag1 & $0.0519 * * *(0.0054)$ & & \\
EmRP*RePat & & & $0.0410^{* * *(0.0069)}$ & \\
EmRP_lag1* RePat & & & $0.0466 * * *(0.0072)$ & \\
REPO* RePat & & & & $0.0912 * * *(0.1120)$ \\
\hline
\end{tabular}




\begin{tabular}{|c|c|c|c|c|}
\hline$\overline{\text { REPO_lag1* RePat }}$ & & & & $0.1032 * * *(0.0589)$ \\
\hline GDP & $-.0306 * * *(0.0033)$ & $-0.0375 * * *(0.0046)$ & $-0.0323 * * *(0.0042)$ & $-0.0391 * * *(0.0051)$ \\
\hline CEXP & $0.0158(0.0020)$ & $0.0162(0.0017)$ & $0.0183 *(0.0021)$ & $0.0204(0.0018)$ \\
\hline EDU & $0.2491 *(0.0248)$ & $0.3466(0.0516)$ & $0.3157(0.0346)$ & $0.0112(0.1737)$ \\
\hline RePat & $0.0006^{* *}(0.0002)$ & $0.0010^{* *}(0.0001)$ & $0.0009 * * *(0.0003)$ & $0.0013(0.0002)$ \\
\hline Pop & $-0.0122 * *(0.0046)$ & $-0.0239 * * *(0.0054)$ & $-0.0126 * * *(0.0051)$ & $-0.0301 * *(0.0056)$ \\
\hline InvP & $0.0193 * * *(0.0177)$ & $0.0201 * * *(0.0170)$ & $0.0234 * * *(0.0186)$ & $0.0355^{* * *}(0.0199)$ \\
\hline \multirow[t]{2}{*}{$\mathrm{AR}(1)$ test } & -2.2932 & -2.1575 & -2.3024 & -2.1235 \\
\hline & {$[0.023]$} & {$[0.019]$} & {$[0.023]$} & {$[0.013]$} \\
\hline \multirow[t]{2}{*}{$\mathrm{AR}(2)$ test } & -1.3401 & -1.2380 & -1.2552 & -1.1895 \\
\hline & [0.1749] & [0.1382] & [0.1411] & [0.1312] \\
\hline \multirow[t]{2}{*}{ Sargan test } & 21.3771 & 17.8685 & 20.1098 & 15.596 \\
\hline & {$[0.0752]$} & [0.1123] & {$[0.0706]$} & [0.1269] \\
\hline \multirow[t]{2}{*}{ Wald test } & 198472.3 & 232216 & 300239.2 & 291644.1 \\
\hline & {$[0]$} & {$[0]$} & {$[0]$} & {$[0]$} \\
\hline $\mathrm{N}$ & 240 & 240 & 240 & 240 \\
\hline
\end{tabular}

Note: $* * * / 1 \%$ significant level; $* * / 5$ significant level and $* / 10$ significant level

The study mentioned above carries some limitations as the moderating effects model fails model to explore the nonlinear causality between energy policy and EPI, confirm the rationality 448 of sample interval segment to reduce the errors in model estimate. The following section of 449 this study addresses the energy policy variable as the threshold dependent variable to form a threshold effect model as below:

$$
E P I_{i t}=\alpha+\beta_{1} E P I_{i t-1}+\beta_{2} E R_{i, t} \circ I\left(Q_{i} \leq \mathrm{C}\right)+\delta_{1} E R_{i, t} \circ I\left(Q_{i}>\mathrm{C}\right)+\sum_{k=1}^{5} \delta_{k} X_{k i t}+\alpha_{i}+
$$

$$
u_{t}+\varepsilon_{i t}
$$

453 In this model above, $C$ is the estimated threshold value, and $I(\cdot)$ is the symptomatic function, 454 which will be true if the corresponding condition is equal to 1 and false if the value is 0 . The 455 test results might come up with the presence of multiple thresholds, which can further be 456 stretched to double and numerous threshold models from the base single threshold model. 


\subsubsection{Analysis of Threshold Regression Test}

We first checked the number of thresholds to perform threshold regression analysis. In

this study, we used Hansen's threshold panel model, used bootstrap technology, and repeated

460 it 500 times to test the threshold. We found that the impact of pollution mitigation policies and

461 clean energy policies on the environmental efficiency index has a major dual-threshold effect,

462 in which energy policy is the threshold component. The results of the importance assessment

463 are summarized in Table 6. The impact of agricultural systems on carbon emissions can be

464 seen in Model 1, while the impact of urbanization on carbon emissions can be seen in Model

465 2. The single-value and dual-value P-value threshold models passed the $1 \%$ significance test

466 (as shown in Model 1), so it can be inferred that there is a dual-threshold effect. The estimated

467 thresholds are 0.240 and 0.82 and each estimated threshold falls within the $95 \%$ confidence

468 interval $[0.225,0.692]$ and $[0.692,0.817]$ respectively, because the single threshold and dual-

469 threshold models have passed. The $1 \%$ significance test also has a potent dual-threshold effect

470 in Model 2. The estimated thresholds are 0.762 and 0.823 and [0.801, [2.163] and [0.762, 2.361]

471 are the corresponding $95 \%$ confidence intervals (table 7 ).

$472 \quad$ Table 6. Results of threshold test.

\begin{tabular}{lccccccc}
\hline & Threshold test & F-value & \multirow{2}{*}{ P-value } & \multicolumn{3}{c}{ Critical value } \\
\cline { 6 - 7 } \cline { 5 - 6 } & & & & $\mathbf{1 \%}$ & $\mathbf{5 \%}$ & $\mathbf{1 0 \%}$ \\
\cline { 6 - 7 } Model 1 & Single & $52.589 * * *$ & 0.000 & 24.557 & 14.670 & 10.134 \\
& Double & $28.661 * * *$ & 0.008 & 24.734 & 15.678 & 10.940 \\
\multirow{2}{*}{ Model 2} & Single & $57.481 * * *$ & 0.000 & 24.521 & 14.987 & 10.623 \\
& Double & $27.229 * * *$ & 0.000 & 2.893 & -5.832 & -11.843 \\
\hline
\end{tabular}

473

Table 7. Estimated threshold variables.

\begin{tabular}{cccc}
\hline Threshold variables & & Estimated thresholds & 95\% confidence interval \\
\hline Model 1 & $\gamma 1$ & 0.240 & {$[0.220,2.762]$} \\
Model 2 & $\gamma_{2}$ & 0.821 & {$[0.762,2.823]$} \\
& $\gamma_{1}$ & 0.762 & {$[0.801,2.163]$} \\
& $\gamma_{2}$ & 0.823 & {$[0.762,2.361]$} \\
\hline
\end{tabular}

474 
Figure 3 shows the result of the likelihood ratio (LR) function. The likelihood ratio (LR)

476 function of the dual-threshold model is used to test the consistency of the threshold estimate to

477 better understand the authenticity and confidence interval of the threshold estimate. When the

478 LR value is 0 , the regional environmental performance index is the threshold estimate. As

479 shown in Figure 3, when the LR value is 0, the corresponding threshold parameters of the

480 provincial environmental performance index are 0.346 and 0.456 , respectively. The threshold

481 estimate is the interval of the provincial environmental performance index. When the

confidence interval is $95 \%$, it is less than $\mathrm{LR}=6.503$. Therefore, the confidence intervals of the threshold estimates of 0.324 and 0.447 are $[0.030,0.709],[0.038,0.539]$. Since the corresponding confidence interval contains two threshold estimates, the threshold estimate is consistent with the true value of the threshold. That is, the authenticity is used to test the two threshold estimates of the dual-threshold model. The specific distribution is shown in Table 3.

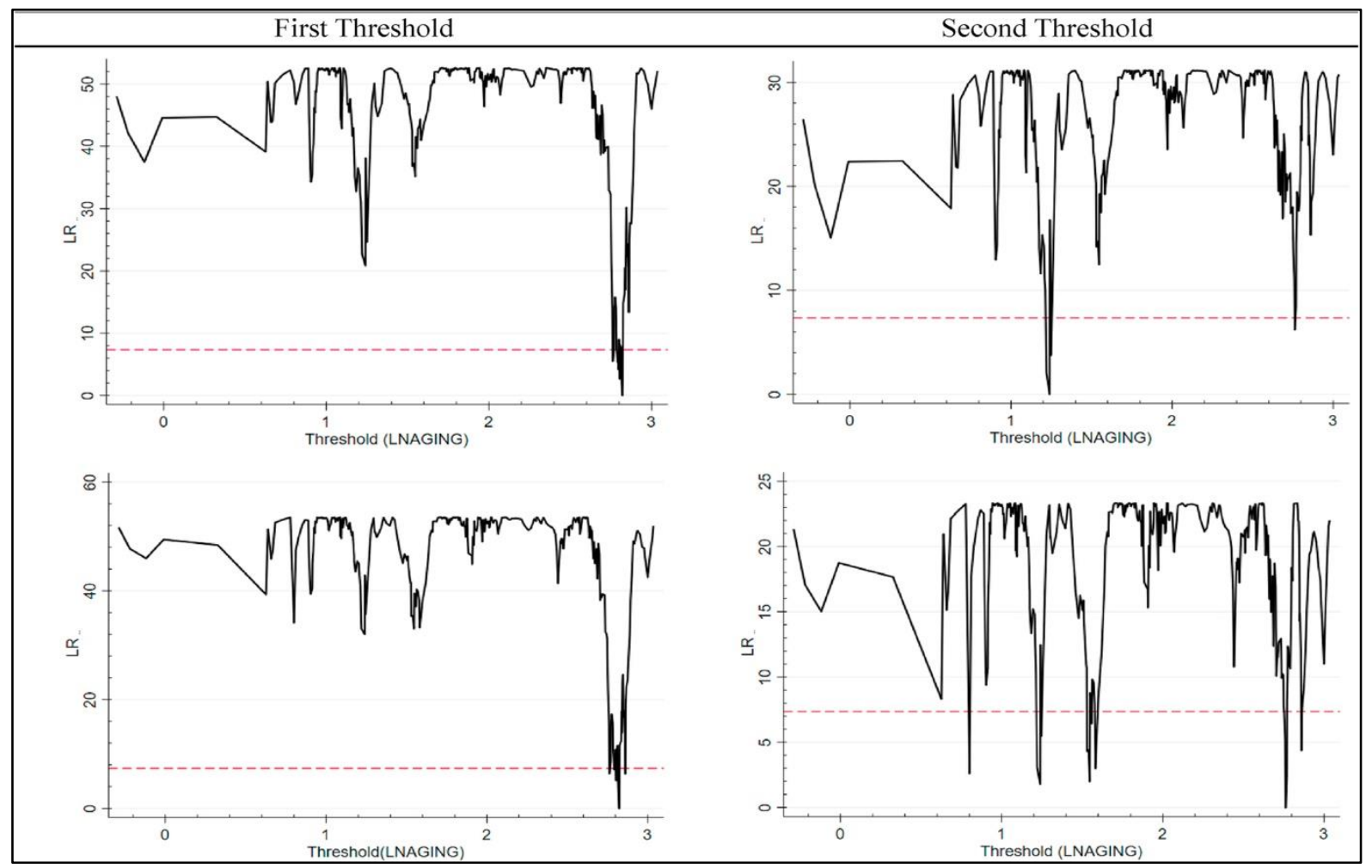


Table 8. The level of Provincial environmental performance with respect to the threshold value

\begin{tabular}{|c|c|c|}
\hline & Medium threshold & $\begin{array}{l}\text { High } \\
\text { threshold }\end{array}$ \\
\hline & $0.301<\mathrm{EPI} \leq 0.438$ & $\mathrm{EPI}>0.438$ \\
\hline 2010 & $\begin{array}{l}\text { Anhui, Chongqing, Chongqing, Fujian, Gansu, Guangxi, } \\
\text { Guizhou, Hainan, Heilongjiang, Jiangxi, Jilin, Ningxia, Beijing, Zhejiang, } \\
\text { Qinghai, Shanxi, Xinjiang, Xizang, Yunnan, } \\
\text { Shanxi }\end{array}$ & $\begin{array}{l}\text { Jiangsu, } \\
\text { Shandong, } \\
\text { Guangdong }\end{array}$ \\
\hline 2011 & $\begin{array}{l}\text { Anhui ,Chongqing ,Chongqing ,Fujian ,Gansu, Guangxi, } \\
\text { Guizhou ,Hainan ,Heilongjiang, Inner Mongolia, Jiangxi, } \\
\text { Jilin, Ningxia, Qinghai, Shanxi, Xinjiang, Xizang, } \\
\text { Yunnan, Shanxi }\end{array}$ & $\begin{array}{l}\text { Jiangsu, } \\
\text { Shandong, } \\
\text { Guangdong }\end{array}$ \\
\hline 2012 & $\begin{array}{l}\text { Heilongjiang, Jiangxi, Hainan, Anhui, Shanxi, } \\
\text { Chongqing, Chongqing, Guangxi, Jilin, Shanxi, Fujian, Hebei, Liaoning, } \\
\text { Inner Mongolia, Qinghai, Gansu, Xizang, Ningxia, Henan } \\
\text { Yunnan, Guizhou, Beijing, Xinjiang }\end{array}$ & $\begin{array}{l}\text { Jiangsu, } \\
\text { Zhejiang, } \\
\text { Shandong, } \\
\text { Guangdong }\end{array}$ \\
\hline 2013 & $\begin{array}{l}\text { Heilongjiang, Fujian, Guangxi, Shanghai, Xizang, Hebei, Liaoning, } \\
\text { Jiangxi, Hainan, Chongqing, Jilin, Shanxi, Anhui, Henan, Hubei, } \\
\text { Inner Mongolia, Gansu, Shanxi, Yunnan, Qinghai, Sichuan } \\
\text { Guizhou, Chongqing, Beijing, Ningxia, Xinjiang }\end{array}$ & $\begin{array}{l}\text { Jiangsu, } \\
\text { Zhejiang, } \\
\text { Shandong, } \\
\text { Guangdong }\end{array}$ \\
\hline 2014 & $\begin{array}{l}\text { Heilongjiang, Fujian, Hunan, Shanghai, Yunnan, } \\
\text { Jiangxi, Guangxi, Chongqing, Jilin, Shanxi, Anhui, Hebei, Liaoning, } \\
\text { Inner Mongolia, Shanxi, Xizang, Guizhou, Gansu, Hubei, Hunan, } \\
\text { Chongqing, Hainan, Beijing, Qinghai, Ningxia, Sichuan } \\
\text { Xinjiang }\end{array}$ & $\begin{array}{l}\text { Jiangsu, } \\
\text { Zhejiang, } \\
\text { Shandong, } \\
\text { Henan, } \\
\text { Guangdong }\end{array}$ \\
\hline 2015 & $\begin{array}{l}\text { Heilongjiang, Fujian, Hubei, Shanghai, Sichuan, } \\
\text { Jiangxi, Hunan, Chongqing, Jilin, Shanxi, Anhui, Hebei, Liaoning, } \\
\text { Inner Mongolia, Yunnan, Guizhou, Chongqing, Shanghai, Hubei, } \\
\text { Xizang, Hainan, Guangxi, Beijing, Shanxi, Gansu, Hunan, Sichuan } \\
\text { Qinghai, Ningxia, Xinjiang }\end{array}$ & $\begin{array}{l}\text { Jiangsu, } \\
\text { Zhejiang, } \\
\text { Shandong, } \\
\text { Henan, } \\
\text { Guangdong }\end{array}$ \\
\hline 2016 & $\begin{array}{l}\text { Hainan, Heilongjiang, Fujian, Liaoning, Chongqing, Being, Hebei, } \\
\text { Shanghai, Jiangxi, Anhui, Hunan, Shanxi, Jilin, Inner }{ }_{\text {Liaoning, Shanghai, }} \\
\text { Mongolia, Guizhou, Sichuan, Hubei, Yunnan, Hubei, Hunan, } \\
\text { Chongqing, Henan, Guangxi, Xizang, Shanxi, Gansu, Sichuan } \\
\text { Qinghai, Ningxia, Xinjiang }\end{array}$ & $\begin{array}{l}\text { Jiangsu, } \\
\text { Zhejiang, } \\
\text { Shandong, } \\
\text { Henan, } \\
\text { Guangdong }\end{array}$ \\
\hline 2017 & $\begin{array}{l}\text { Liaoning, Shanghai, Jiangxi, Jilin, Hainan, Anhui, } \\
\text { Chongqing, Fujian, Inner Mongolia, Hebei, } \\
\text { Heilongjiang, Hebei, } \\
\text { Guizhou, Hunan, Hubei, Beijing, Yunnan, Xizang, Shanghai, } \\
\text { Shanxi, Gansu, Qinghai, Ningxia, Xinjiang }\end{array}$ & $\begin{array}{l}\text { Jiangsu, } \\
\text { Zhejiang, } \\
\text { Shandong, } \\
\text { Henan, } \\
\text { Guangdong }\end{array}$ \\
\hline
\end{tabular}

Table 8 presents the level of provincial environmental performance concerning the threshold values. The number of provinces with an EPI of less than 0.301 increased from $62.3 \%$ to $85.2 \%$ between 2010 and 2017 and showed an upward trend throughout the period. At the same time, provinces with EPI levels between 0.301 and 0.438 increased from $3.2 \%$ to $22.6 \%$, indicating that these provinces' environmental performance has improved during the study 
period. Provinces with an EPI higher than 0.438 also showed a similar steady growth trend.

500 This is happened due to the level of regional economic and technological development

501 continued to increase (Zhang et al., 2020), from $9.7 \%$ to $16.1 \%$, and the regional innovation

502 system continued to shift to the best level. However, after 2013, provinces' environmental

503 performance with a regional economic development level higher than 0.438 has changed.

504 Between 2010 and 2017, the proportion of regions with a regional economic development level

505 of less than 0.438 declined from approximately $90.3-83.9 \%$. The story of regional

506 technological innovation has different positive effects on these regions' regional sustainable

507 development capabilities. During the study period, the proportion of areas where regional

508 technological innovation contributed to promoting sustainable development dropped from $87.1 \%$

509 to $61.3 \%$. Also, during the study period, the proportion of regions where regional technological

510 innovation only had a weak impact on regional sustainable development increased from $3.2 \%$

511 to $22.6 \%$. Therefore, it can be concluded that, overall, the situation in China is optimistic.

512 Table 9. Threshold regression results

\begin{tabular}{|c|c|c|c|c|}
\hline & EmRP & RePO & EmRP & $\mathrm{RePO}$ \\
\hline$\overline{\text { EPI_lag1 }}$ & $0.00499 * * *(0.02)$ & $0.0084 * * *(0.016)$ & $0.00502 * * *(0.02)$ & $0.0079 * * *(0.017)$ \\
\hline EmRP $<\gamma 1$ & $0.0332 * *(0.019)$ & & $0.0274 * *(0.018)$ & \\
\hline$E m R P \geq \gamma 1$ & $0.0805^{* * *}(0.108)$ & & $0.160 * * *(0.069)$ & \\
\hline $\operatorname{RePO}<\gamma 2$ & & $0.0202 *(0.019)$ & & $0.0013 * *(0.04)$ \\
\hline $\mathrm{RePO} \geq \gamma 2$ & & $0.0924 * * *(0.025)$ & & $0.110 * * *(0.045)$ \\
\hline GDP & $-0.707(0.844)$ & $-0.422(1.018)$ & $-0.716(0.848)$ & $-0.363(1.032)$ \\
\hline CEXP & $0.0266(0.119)$ & $0.0794(0.07)$ & $0.0239(0.121)$ & $0.0776(0.07)$ \\
\hline EDU & $0.542 * * *(0.271)$ & $0.201 * * *(0.4)$ & $0.543 * * *(0.274)$ & $0.248 * * *(0.417)$ \\
\hline RePat & $0.217(-0.259)$ & $0.688 * * *(0.208)$ & $0.214(0.269)$ & $0.690 * * *(0.209)$ \\
\hline Pop & $-0.0169 *(0.009)$ & $-0.00538(0.01)$ & $-0.0100(0.009)$ & $-0.00683(0.01)$ \\
\hline InvP & $0.423(0.431)$ & $0.423(0.439)$ & $0.345(0.403)$ & $0.494(0.444)$ \\
\hline EmRP* RePat & $2.234 * * *(0.845)$ & $0.604 * *(0.53)$ & $2.206 * * *(0.848)$ & $0.631 * * *(0.534)$ \\
\hline EmRP_lag1* RePat & $8.138 * *(2.778)$ & $8.409 * * *(3.796)$ & $8.166 * * *(2.764)$ & $7.920 * * *(3.771)$ \\
\hline RePO* RePat & $1.217 * * *(0.468)$ & $0.0310(0.493)$ & $1.133 * *(0.461)$ & $0.0673(0.499)$ \\
\hline RePO_lag1* RePat & $0.466 * * *(0.168)$ & $0.703 * *(0.278)$ & $0.439 * * *(0.166)$ & $0.660 * *(0.291)$ \\
\hline Observations & 240 & 240 & 240 & 240 \\
\hline
\end{tabular}




\begin{tabular}{lllll}
\hline Constant & $2.914(3.099)$ & $0.832(3.56)$ & $2.822(3.121)$ & $0.553(3.607)$ \\
R-squared & 0.441 & 0.109 & 0.439 & 0.101 \\
Threshold Value & 2.15 & 0.09 & 2.146 & 0.08 \\
Threshold Test p-value & 0.047 & 0.00 & 0.146 & 0,00 \\
\hline
\end{tabular}

513

514 Table 9 presents the results of regression for the threshold model. As, the values of

515 emission reduction policies and renewable energy policies exceed the levels of corresponding

516 thresholds, the positive impact of energy policy on environmental performance gradually

517 increases. It is observed that the coefficient estimates for the threshold effect model are 0.0571 ,

518 0.012, respectively, and there is an upbound of their corresponding level of significance from

$5195 \%$ to $1 \%$. This proposes that when the energy policy's pull-out position improves by $1 \%$, the

520 environmental performance increases by $3.32 \%$ to $8 . .05 \%$. It proves that the "J-shape" has a

521 marginal Growth trend. These investigation results depict how different regulations affect the

522 causality between the surrounded position of environmental regulations, the EP, and the

523 threshold or turning point in this relationship.

524

525

526

527

528

529

530

531

532

533

534

535

\section{Discussion and Policy Implication}

This study used no radial Data Envelopment Analysis (DEA) and panel data model for the case of 30 Chinese provinces by taking the panel data from 2010 to 2017 . The results show that economic development can lead to environmental degradation by affecting energy policy and industrial structure but in different directions. Also, the P-values of the single and double threshold models passed the $1 \%$ significant test, so it can be concluded that there is a double threshold effect. The estimated thresholds are 1.240 and 2. 821. Environmental performance index (EPI) score within the range of 0.74 to 1 is evident in Jiangsu, Shandong, Guangdong, Hainan, Zhejiang, Shanghai, and Fujian. In contrast, with the score 0.07-0.26, Shanxi, Chongqing, Yunnan, Xinjiang, Heilongjiang, Sichuan, Hebei, Hubei, Hunan, Guangxi, and Guizhou show lower values. Comparative analysis of the causality and communication mechanism in different situations. Economic development will significantly increase carbon 
emissions, confirmed through data envelopment analysis and econometric estimation. Second.

537 Also, they have become an indirect source of increased carbon emissions by influencing 538 environmental regulations and upgrading the industrial structure. Therefore, the environment 539 is deteriorating, but these two mechanisms are entirely different. It limits the strength of 540 ecological regulations and increases carbon emissions in the context of environmental 541 regulations. On the other hand, it promotes the upgrading of the industrial structure, thereby increasing carbon emissions in the industrial system.

543 Secondly, the impact of energy consumption on carbon dioxide emissions coefficient 544 estimates for the threshold effect model is $0.0571,0.012$, respectively. There is an upbound of 545 their corresponding level of significance from $5 \%$ to $1 \%$. This proposes that when the pull-out 546 position of the environmental regulations improves by $1 \%$, the high emitting industries' total 547 factor energy efficiency increases by $1.2 \%$ to $5.7 \%$. The central region is higher in level and scale than the eastern and western regions. Also, the mechanism has apparent heterogeneity in the east of, west and central regions. Regardless of the environmental regulations or industrial 550 structure, the central area's transmission path is much more important and more extensive than 551 that in the eastern and western regions. This phenomenon may affect environmental regulations and industrial structure. However, this insignificant impact hinders the transmission path in the region of the west.

554 The study pointed out that revenue must match responsibilities so that local governments 555 have both financial resources and corresponding environmental management rights and 556 obligations to improve environmental quality. Also, making full use of transfer payments, tax 557 rebates, and other support systems to enhance the environmental governance and public service capabilities of local governments is another thing that needs to be done to stimulate the enthusiasm and efficiency of local governments in protecting the environment. 
Next, policymakers should pay close attention to the distorting effects of energy consumption on local government behavior and are optimistic that they will maintain close supervision to improve environmental governance efficiency. Therefore, it is necessary to

563 reduce pollution through coexistence and flexible government expenditure in environmental

564 protection and monitoring environmental protection.

565 An increase in environmental protection expenditures will help formulate pollution transmission in underdeveloped areas and financial self-sufficiency areas. In contrast, developed areas with strong economic capacity need to improve environmental supervision

568 further. This will help prevent the government's production expenditures from squeezing out

569 fiscal expenses related to technological innovation.

570 This is also conducive to changing the phenomenon that the upgrading of the industrial structure leads to an increase in pollution emissions, which weakens the second stage of the transmission path (related to media effects) and reduces the negative impact on the 573 environment.

574 Ethical Approval and Consent to Participate: The authors declare that they have no known 575 competing financial interests or personal relationships that seem to affect the work reported in 576 this article. We declare that we have no human participants, human data or human tissues.

\section{Consent for Publication:}

$578 \quad$ N/A

579 Author Contribution: Muhammad Ghazanfar Abbas: Conceptualization, Data curation,

580 Methodology, Writing - original draft. Wang Zhuquan: Data curation, Visualization, 581 supervision. Hafeez Ullah : Visualization, editing. Wasim Iqbal: review \& editing. 582 Muhammad Hafeez: Writing - review \& editing, and software. Shahid Bashir: Writing - review 583 \& editing 
Funding: This research did not receive any specific grant from funding agencies in the public,

commercial, or not-for-profit sectors.

586 Competing interest statement: The authors declare no conflict of interest.

587 Availability of data and materials: The data can be available on request

611

612

613

614

615

616

617

618

619

620

621

622

623

624

625

626

627

628

629

630

631

632

633

\section{Reference}

Abbas, Q., Nurunnabi, M., Alfakhri, Y., Khan, W., Hussain, A., Iqbal, W., 2020. The role of fixed capital formation, renewable and non-renewable energy in economic growth and carbon emission: a case study of Belt and Road Initiative project. Environ. Sci. Pollut. Res. 27, 4547645486. https://doi.org/10.1007/s11356-020-10413-y

Adedoyin, F.F., Ozturk, I., Agboola, M.O., Agboola, P.O., Bekun, F.V., 2021. The implications of renewable and non-renewable energy generating in Sub-Saharan Africa: The role of economic policy uncertainties. Energy Policy 150, 112115. https://doi.org/https://doi.org/10.1016/j.enpol.2020.112115

Alam, M.S., Atif, M., Chien-Chi, C., Soytaş, U., 2019. Does corporate R\&D investment affect firm environmental performance? Evidence from G-6 countries. Energy Econ. 78, 401-411. https://doi.org/10.1016/j.eneco.2018.11.031

Anser, M.K., Iqbal, W., Ahmad, U.S., Fatima, A., Chaudhry, I.S., 2020. Environmental efficiency and the role of energy innovation in emissions reduction. Environ. Sci. Pollut. Res. 27, 2945129463. https://doi.org/10.1007/s11356-020-09129-w

Banker, R.D., 1984. Estimating most productive scale size using data envelopment analysis. Eur. J. Oper. Res. 17, 35-44. https://doi.org/10.1016/0377-2217(84)90006-7

Böhringer, C., Cuntz, A., Harhoff, D., Asane-Otoo, E., 2017. The impact of the German feed-in tariff scheme on innovation: Evidence based on patent filings in renewable energy technologies. Energy Econ. 67, 545-553. https://doi.org/10.1016/j.eneco.2017.09.001

Cariola, A., Fasano, F., La Rocca, M., Skatova, E., 2020. Environmental sustainability policies and the value of debt in EU SMEs: Empirical evidence from the energy sector. J. Clean. Prod. 275, 123133. https://doi.org/https://doi.org/10.1016/j.jclepro.2020.123133

Charnes, A., Cooper, W.W., Rhodes, E., 1978. Measuring the efficiency of decision making units. Eur. J. Oper. Res. 2, 429-444. https://doi.org/10.1016/0377-2217(78)90138-8

Chen, X., Lin, B., 2020. Energy and CO2 emission performance: A regional comparison of China's non-ferrous metals industry. J. Clean. Prod. 274. https://doi.org/10.1016/j.jclepro.2020.123168

Du, W., Wang, F., Li, M., 2020. Effects of environmental regulation on capacity utilization: Evidence from energy enterprises in China. Ecol. Indic. 113. https://doi.org/10.1016/j.ecolind.2020.106217

Farrell, M.J., 1957. The Measurement of Productive Efficiency. J. R. Stat. Soc. Ser. A 120, 253. https://doi.org/10.2307/2343100

Galeotti, M., Salini, S., Verdolini, E., 2020. Measuring environmental policy stringency: Approaches, validity, and impact on environmental innovation and energy efficiency. Energy Policy 136, 111052. https://doi.org/https://doi.org/10.1016/j.enpol.2019.111052

Geng, Z., Zeng, R., Han, Y., Zhong, Y., Fu, H., 2019. Energy efficiency evaluation and energy saving based on DEA integrated affinity propagation clustering: Case study of complex petrochemical industries. Energy 179, 863-875. https://doi.org/10.1016/j.energy.2019.05.042

Guo, R., Yuan, Y., 2020. Different types of environmental regulations and heterogeneous influence on energy efficiency in the industrial sector: Evidence from Chinese provincial data. Energy Policy 145. https://doi.org/10.1016/j.enpol.2020.111747

Hansen, B.E., 1999. Threshold effects in non-dynamic panels: Estimation, testing, and inference. J. Econom. 93, 345-368. https://doi.org/10.1016/S0304-4076(99)00025-1

Hodson, E.L., Brown, M., Cohen, S., Showalter, S., Wise, M., Wood, F., Caron, J., Feijoo, F., Iyer, G., Cleary, K., 2018. U.S. energy sector impacts of technology innovation, fuel price, and electric sector CO2 policy: Results from the EMF 32 model intercomparison study. Energy 
Hou, Y., Iqbal, W., Shaikh, G.M., Iqbal, N., Solangi, Y.A., Fatima, A., 2019. Measuring energy efficiency and environmental performance: A case of South Asia. Processes 7, 325. https://doi.org/10.3390/pr7060325

Inman, O.L., Anderson, T.R., Harmon, R.R., 2006. Predicting U.S. jet fighter aircraft introductions from 1944 to 1982: A dogfight between regression and TFDEA. Technol. Forecast. Soc. Change 73, 1178-1187. https://doi.org/10.1016/j.techfore.2006.05.013

Iqbal, W., Altalbe, A., Fatima, A., Ali, A., Hou, Y., 2019a. A DEA approach for assessing the energy, environmental and economic performance of top 20 industrial countries. Processes 7, 902. https://doi.org/10.3390/PR7120902

Iqbal, W., Fatima, A., Yumei, H., Abbas, Q., Iram, R., 2020. Oil supply risk and affecting parameters associated with oil supplementation and disruption. J. Clean. Prod. 255. https://doi.org/10.1016/j.jclepro.2020.120187

Iqbal, W., Yumei, H., Abbas, Q., Hafeez, M., Mohsin, M., Fatima, A., Jamali, M.A., Jamali, M., Siyal, A., Sohail, N., 2019b. Assessment of wind energy potential for the production of renewable hydrogen in Sindh Province of Pakistan. Processes 7, 196. https://doi.org/10.3390/pr7040196

Iqbal, W., Yumei, H., Abbas, Q., Hafeez, M., Mohsin, M., Fatima, A., Jamali, M.A., Jamali, M., Siyal, A., Sohail, N., 2019c. Assessment of wind energy potential for the production of renewable hydrogen in Sindh Province of Pakistan. Processes 7. https://doi.org/10.3390/pr7040196

Khoshnevisan, B., Rafiee, S., Omid, M., Mousazadeh, H., 2013. Reduction of CO2 emission by improving energy use efficiency of greenhouse cucumber production using DEA approach. Energy 55, 676-682. https://doi.org/10.1016/J.ENERGY.2013.04.021

Koopmann, T.C., 1951. An analysis of production as an efficient combination of activities, Proceedings of a Conference, in: Activity Analysis of Production and Allocation. pp. 33-97.

Li, J., Lin, B., 2017. Does energy and CO2 emissions performance of China benefit from regional integration? Energy Policy 101, 366-378. https://doi.org/10.1016/j.enpol.2016.10.036

Li, K., Lin, B., 2016. Impact of energy technology patents in China: Evidence from a panel cointegration and error correction model. Energy Policy 89, 214-223. https://doi.org/10.1016/j.enpol.2015.11.034

Lin, B., Chen, X., 2019. Evaluating the CO2 performance of China's non-ferrous metals Industry: A total factor meta-frontier Malmquist index perspective. J. Clean. Prod. 209, 1061-1077. https://doi.org/10.1016/j.jclepro.2018.10.278

Lin, B., Jia, Z., 2019. How does tax system on energy industries affect energy demand, CO2 emissions, and economy in China? Energy Econ. 84. https://doi.org/10.1016/j.eneco.2019.104496

Liu, H., Fan, J., Zeng, Y., Guo, R., 2019. Spatio-temporal differences in carbon intensity in highenergy-intensive industry and its influence factors in China. Shengtai Xuebao/ Acta Ecol. Sin. 39, 8357-8369. https://doi.org/10.5846/stxb201809121957

Ma, D., Fei, R., Yu, Y., 2019. How government regulation impacts on energy and CO2 emissions performance in China's mining industry. Resour. Policy 62, 651-663. https://doi.org/10.1016/j.resourpol.2018.11.013

Meng, L., Li, Y., Zhang, S., 2020. Regional differences of carbon emissions in the coal industry based on FPGA and wireless sensors. Microprocess. Microsyst. 103489. https://doi.org/10.1016/j.micpro.2020.103489

Miyamoto, M., Takeuchi, K., 2019. Climate agreement and technology diffusion: Impact of the Kyoto Protocol on international patent applications for renewable energy technologies. Energy Policy 129, 1331-1338. https://doi.org/10.1016/j.enpol.2019.02.053

Nassiri, S.M., Singh, S., 2009. Study on energy use efficiency for paddy crop using data envelopment analysis (DEA) technique. Appl. Energy 86, 1320-1325. https://doi.org/10.1016/j.apenergy.2008.10.007

Ozturk, I., Acaravci, A., 2010. CO2 emissions, energy consumption and economic growth in Turkey. Renew. Sustain. Energy Rev. https://doi.org/10.1016/j.rser.2010.07.005

Öztürk, R.Ç., Altınok, İ., 2021. Genetic population structure of the striped venus clam Chamelea 

gallina across its range. Fish. Res. 234, 105758. https://doi.org/10.1016/j.fishres.2020.105758 Shao, C., Guan, Y., Wan, Z., Chu, C., Ju, M., 2014. Performance analysis of CO2 emissions and energy efficiency of metal industries in China. J. Environ. Manage. 134, 30-38. https://doi.org/10.1016/j.jenvman.2013.12.025

Song, M.-L., Zhang, L.-L., Liu, W., Fisher, R., 2013. Bootstrap-DEA analysis of BRICS' energy efficiency based on small sample data. Appl. Energy 112, 1049-1055. https://doi.org/10.1016/J.APENERGY.2013.02.064

Usman, A., Ozturk, I., Hassan, A., Maria Zafar, S., Ullah, S., 2021. The effect of ICT on energy consumption and economic growth in South Asian economies: An empirical analysis. Telemat. Informatics 58, 101537. https://doi.org/10.1016/j.tele.2020.101537

Wang, Q., Li, S., Pisarenko, Z., 2020. Heterogeneous effects of energy efficiency, oil price, environmental pressure, R\&D investment, and policy on renewable energy - evidence from the G20 countries. Energy 209, 118322. https://doi.org/10.1016/j.energy.2020.118322

Wang, Z., He, W., Wang, B., 2017. Performance and reduction potential of energy and CO2 emissions among the APEC's members with considering the return to scale. Energy 138, 552562. https://doi.org/10.1016/j.energy.2017.07.059

Wu, H., Hao, Y., Ren, S., 2020. How do environmental regulation and environmental decentralization affect green total factor energy efficiency: Evidence from China. Energy Econ. 91. https://doi.org/10.1016/j.eneco.2020.104880

Yu, X., Wang, P., 2021. Economic effects analysis of environmental regulation policy in the process of industrial structure upgrading: Evidence from Chinese provincial panel data. Sci. Total Environ. 753, 142004. https://doi.org/https://doi.org/10.1016/j.scitotenv.2020.142004

Zhang, W.W., Zhao, B., Gu, Y., Sharp, B., Xu, S.C., Liou, K.N., 2020. Environmental impact of national and subnational carbon policies in China based on a multi-regional dynamic CGE model. J. Environ. Manage. 270. https://doi.org/10.1016/j.jenvman.2020.110901 
Figures

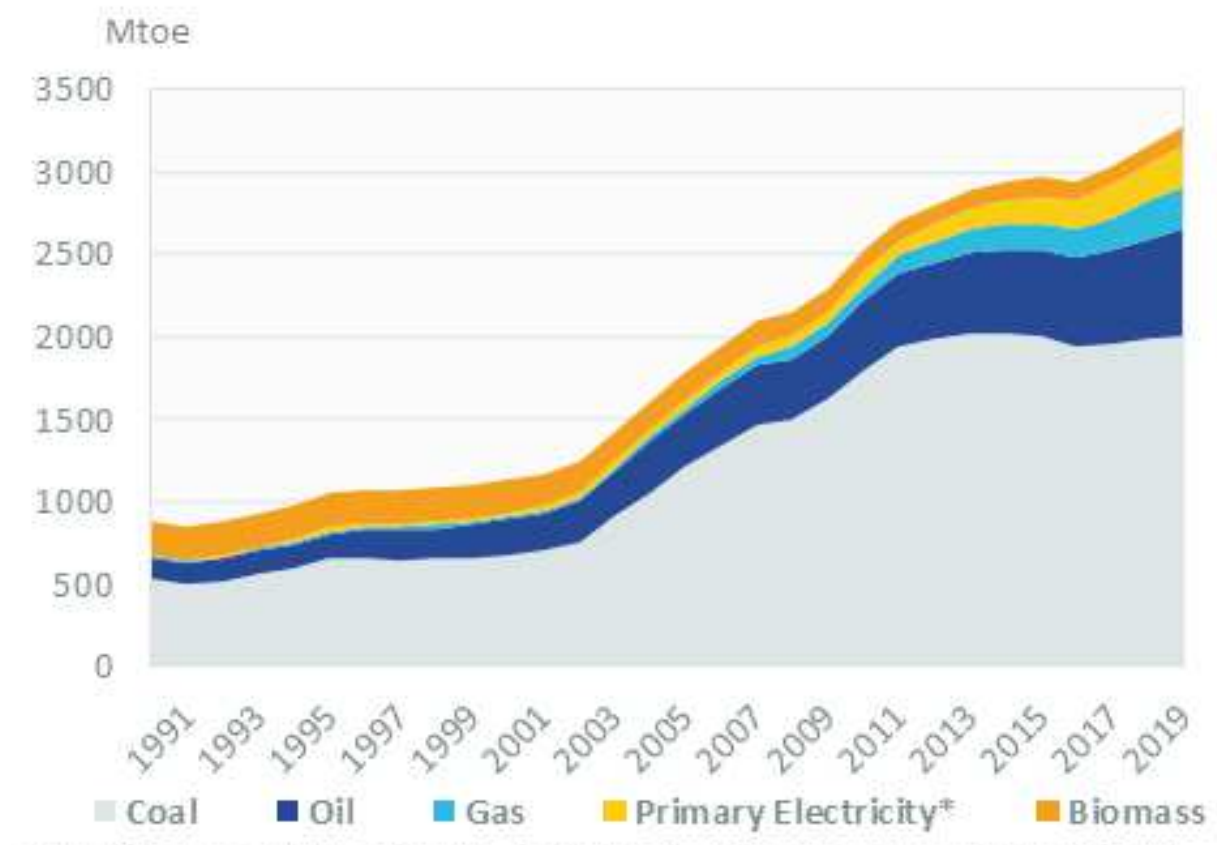

*including heat; Nuclear (1TWh $=0.26 \mathrm{Mtoe})$, Hydroelectricity and wind $(1 \mathrm{TWh}=$ $0.086 \mathrm{Mtoe}$ ), Geothermal ( $1 \mathrm{TWh}=0.86 \mathrm{Mtoe}$ )

\section{Figure 1}

Energy consumption by source 


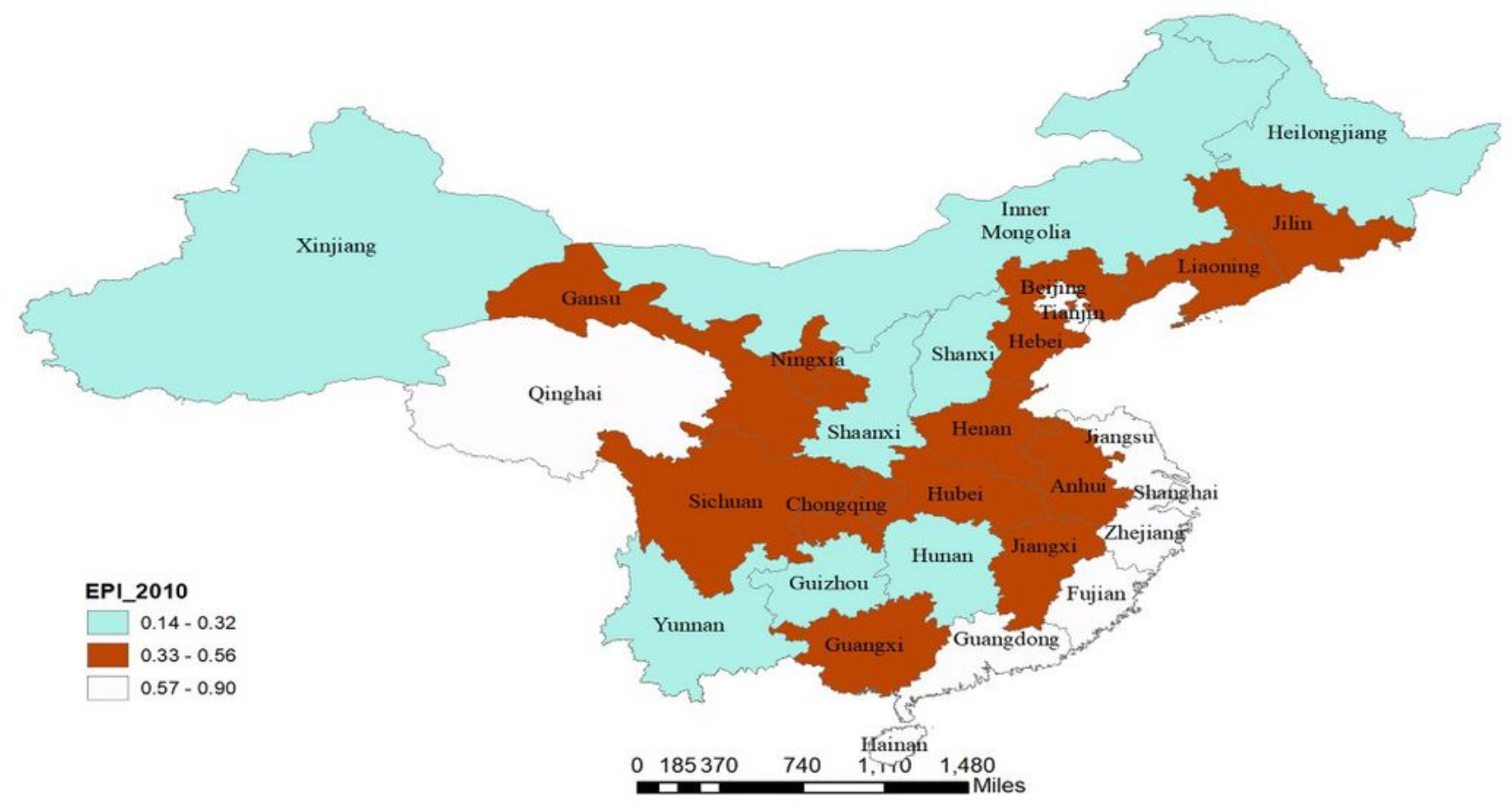

Figure_a

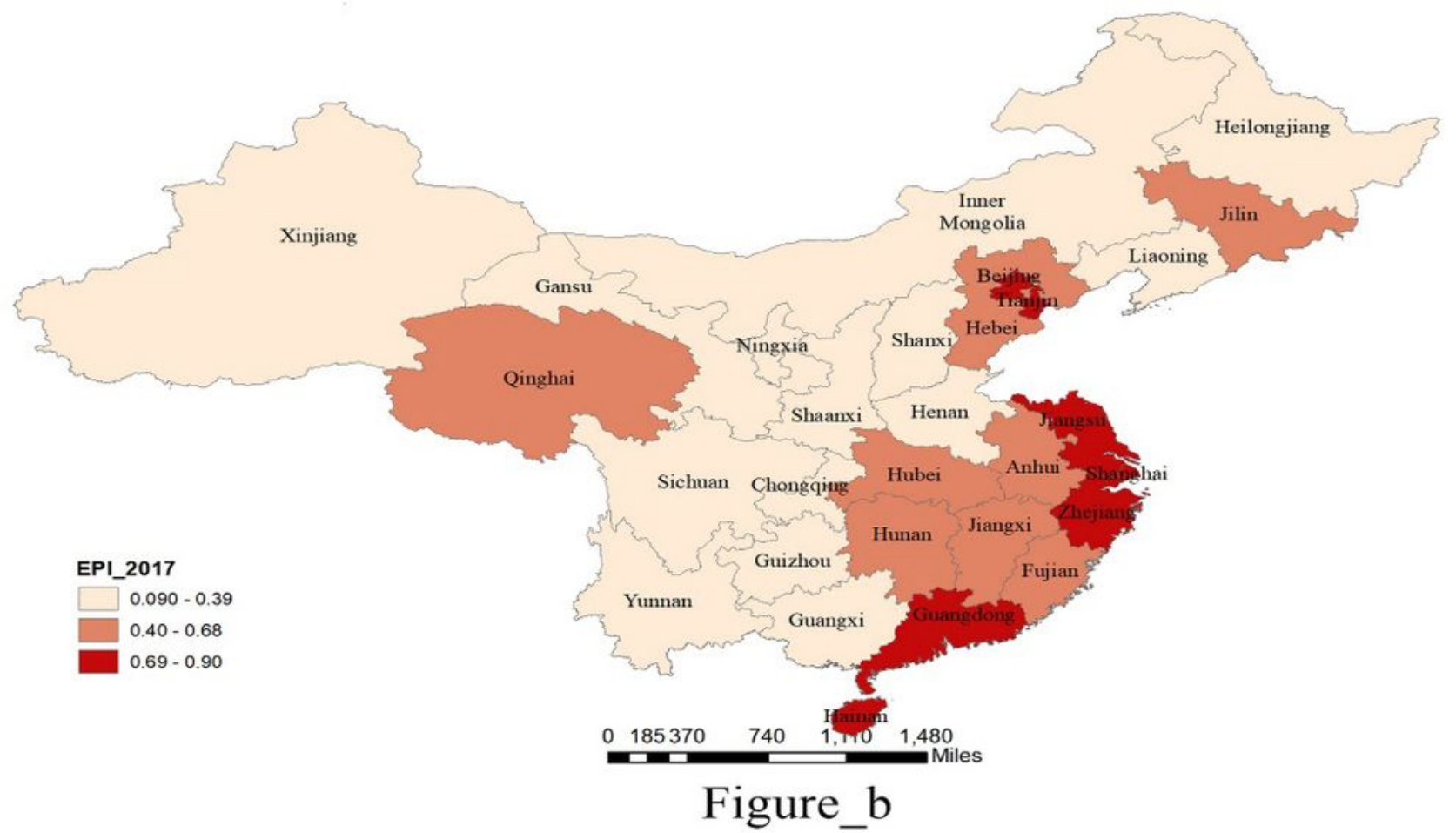

\section{Figure 2}

The spatial distribution of EPI in 2010 and 2017 Note: The designations employed and the presentation of the material on this map do not imply the expression of any opinion whatsoever on the part of Research Square concerning the legal status of any country, territory, city or area or of its authorities, or concerning the delimitation of its frontiers or boundaries. This map has been provided by the authors. 


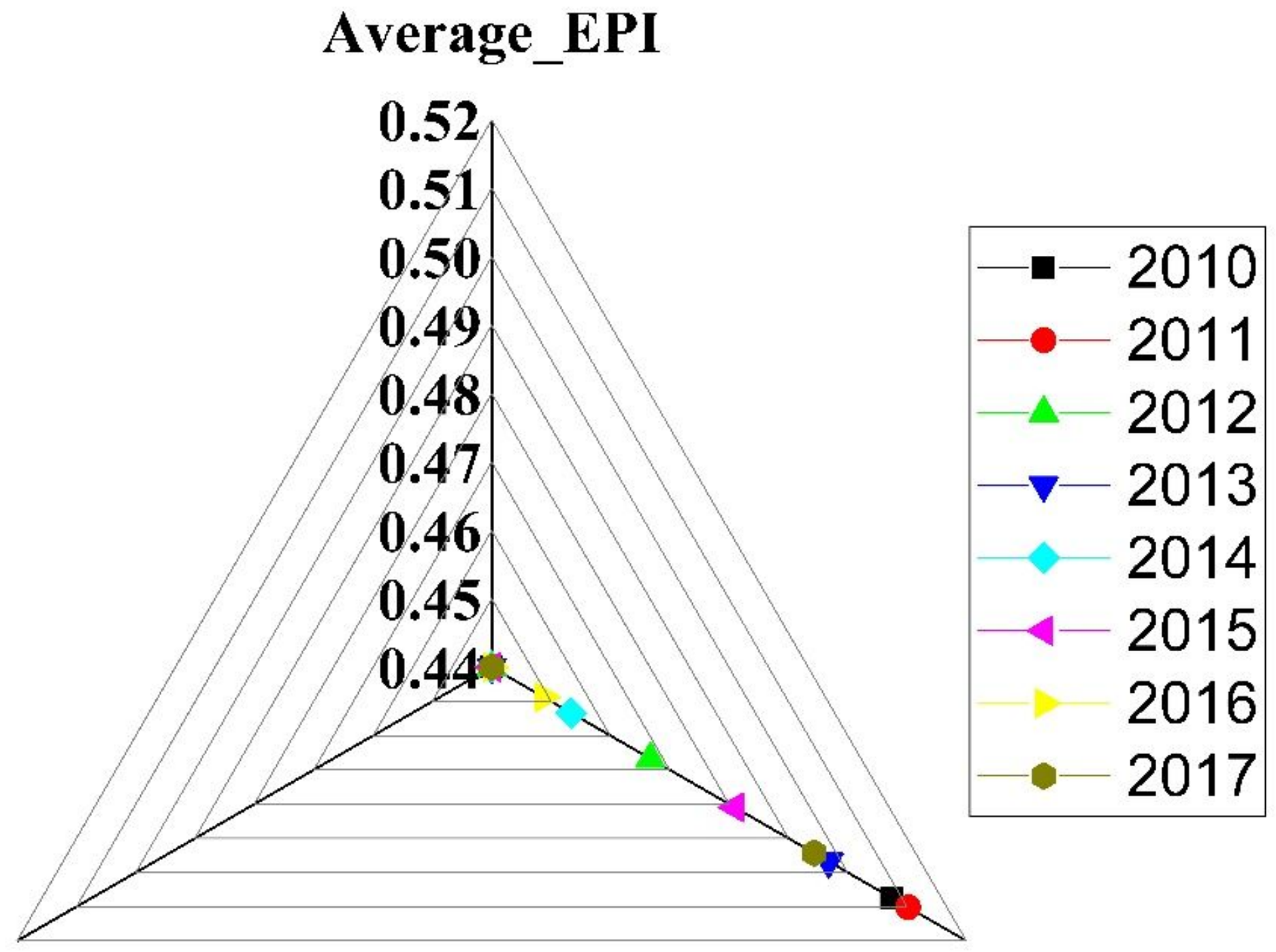

Figure 3

The average EPI of China's at the provincial level from 2010 to 2017 


\section{First Threshold}
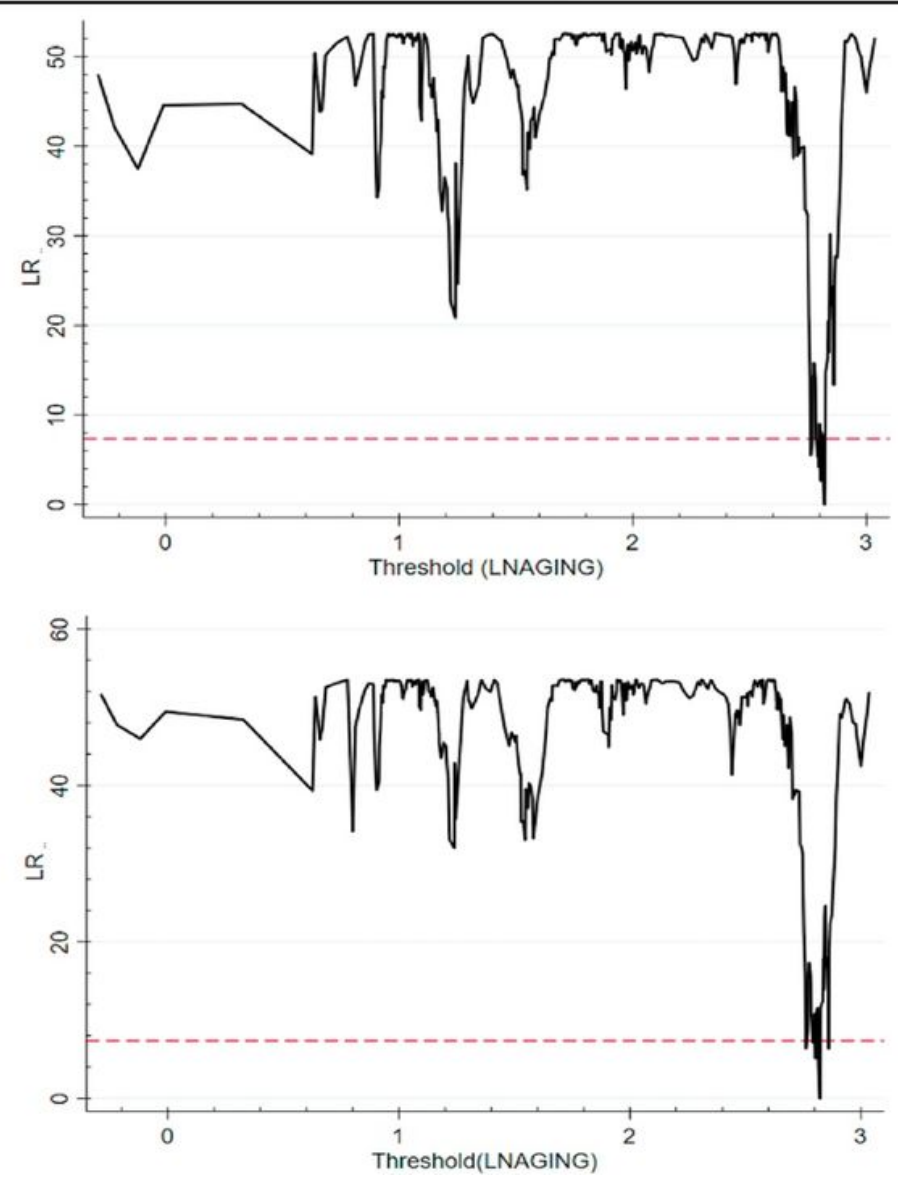

Second Threshold
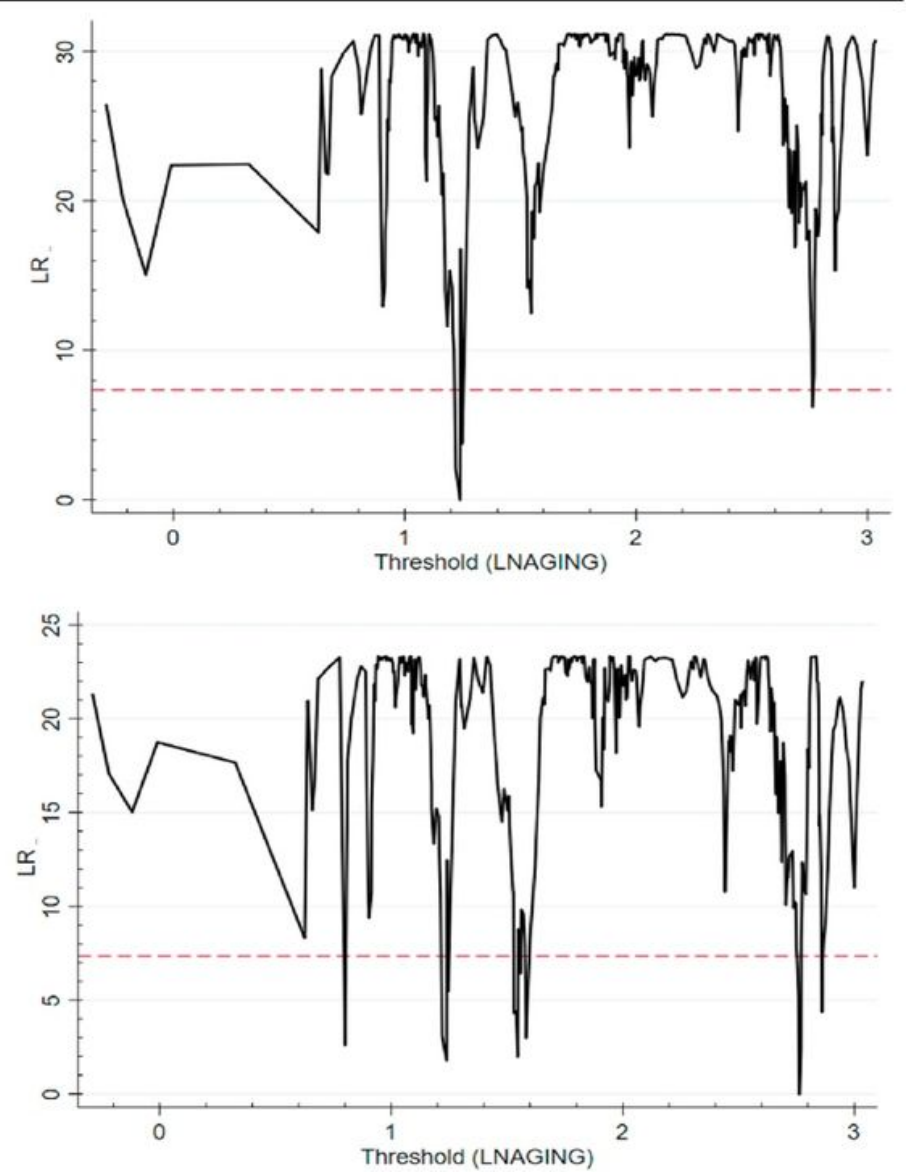

Figure 4

The likelihood ratio of Model 1 and Model 2 